PART III

Climate Variations of Tropical Cyclone Activity 
March 13, $2010 \quad$ 10:34 B-936 b936-ch09

Chapter 9

\title{
Tropical Cyclones and Climate Change: A Review
}

\author{
Thomas Knutson \\ NOAA/Geophysical Fluid Dynamics Laboratory, \\ 201 Forrestal Road, Princeton, NJ 08542, USA \\ tom.knutson@noaa.gov \\ Chris Landsea \\ NOAA/NWS/National Hurricane Center, \\ 11691 S.W. 17th Street, Miami, FL 33165-2149, USA \\ chris.landsea@noaa.gov \\ Kerry Emanuel \\ Massachusetts Institute of Technology, \\ 77 Mass. Avenue, Cambridge, MA 02139, USA \\ emanuel@mit.edu
}

\begin{abstract}
A review of the science on the relationship between climate change and tropical cyclones (TCs) is presented. Topics include changes in aspects of tropical climate that are relevant to TC activity; observed trends and low-frequency variability of TC activity; paleoclimate proxy studies; theoretical and modeling studies; future projections; roadblocks to resolution of key issues; and recommendations for making future progress.
\end{abstract}

\section{Introduction}

This report reviews the current state-ofthe-science on possible relationships between climate variability and change and tropical cyclone (TC) activity on different time scales. The emphasis here is on multidecadal variability and longer time scale changes, including possible anthropogenic influences on tropical cyclone activity.

The present report is not a scientific assessment of anthropogenic influence on TCs, as we do not present likelihood statements on various key issues, as is done for example in the IPCC (Intergovernmental Panel on Climate Change) assessments. Several previous assessment reports contain specific statements on possible anthropogenic influence on TCs.
One such assessment (Henderson-Sellers et al., 1998) concluded: (i) there was no clear evidence for long-term trends in TC activity; (ii) the potential intensity (PI) of storms would remain the same or increase by $10-20 \%$ (in terms of central pressure fall) for a doubling of $\mathrm{CO}_{2}$ ) although uncertainties remained with PI approaches; (iii) little could be said about the future distribution of intensities or about future frequencies of TCs; and (iv) the broad geographic regions of cyclogenesis and of occurrence of TCs were unlikely to change significantly. A 10-20\% increase in central pressure fall would correspond to a smaller (roughly $5-10 \%$ ) percentage increase in terms of maximum surface wind speeds. Other more recent assessments of this issue include WMO (2006), IPCC (2007), and CCSP (2008). WMO (2006) concluded that 
while there was evidence both for and against the existence of a detectable anthropogenic signal in the tropical cyclone record, no firm conclusion could be made on that point. IPCC (2007) concluded that it was "more likely than not" (meaning $>50 \%$ chance) that human activities have contributed to the observed trend in intense tropical cyclone activity in some regions since 1970. CCSP (2008) concluded that "There is evidence suggesting a human contribution to recent changes in hurricane activity ... though a confident assessment will require further study." A review and discussion of the tropical cyclones and climate problem from the viewpoint of the climate change detection and attribution methodologies is given by Walsh et al. (2008).

The present report attempts to briefly summarize earlier published research, but with a greater emphasis on work published since the Henderson-Sellers et al. (1998) and Walsh (2004) reviews were completed, including more recent published work on trends in observed past TC metrics and updated TC climate projections. We do not include a focus on societal impacts of TCs in this review, while recognizing that this topic presents a further important perspective on historical records (e.g., Pielke, 2005; Pielke et al., 2008) and projections.

\section{Background on Tropical Climate Changes Relevant to Tropical Cyclone Activity}

There is substantial evidence that the largescale environment in which hurricanes form and evolve is changing as a result of anthropogenic emissions of greenhouse gases and aerosols. The most recent assessment of this problem is given in IPCC (2007), which concludes that most of the globally averaged temperature increase since the mid-20th century is very likely (>90\% chance) due to the observed increase in human-caused greenhouse gas concentrations. A study of subsurface ocean data by Barnett et al. (2005) concluded that an anthropogenic warming signal is penetrating the world oceans, in broad agreement with model simulations that include the greenhouse gas forcing. Modelbased attribution of early 20th century global warming (e.g., 1900-1944) to specific causes is more ambiguous, with various studies suggesting significant contributions from multiple factors, including increased greenhouse gases, solar variability, decreasing volcanic activity, and internal climate variability (e.g., Stott et al., 2000; Delworth and Knutson, 2000; Meehl et al., 2004; Knutson et al., 2006).

\subsection{Tropical Atlantic Warming: Natural Variability vs. Anthropogenic Forcing}

Some aspects of the tropical climate of relevance to hurricane activity appear to be changing in a trend-like fashion. Based primarily on climate model assessments, there is increasing evidence that sea surface temperature increases in tropical cyclone basins, as reported in several studies (e.g., Emanuel, 2005a; Webster et al., 2005), are at least partly a response to long-term increases in greenhouse gas concentrations. For example, Santer et al. (2006) find that observed SST increases in the Atlantic and North Pacific tropical cyclogenesis regions during the 20th century are unlikely to be due solely to unforced variability of the climate system, but are more realistically simulated in experiments using estimated historical climate forcing. Their internal climate variability assessment and external forcing results are made more robust by their use of 22 different climate models and two observed SST reconstructions. Using the models for which individual forcing experiments were available, they find that the human-induced change in greenhouse gas forcing is the main cause of the 20th century warming, and particularly of the late 20th century warming. Their results support earlier regional surface temperature trend assessments based on a more limited set (two) of models (Knutson et al., 2006) or on a more limited set of forcings (Karoly and $\mathrm{Wu}, 2005)$ both of which found model-based 
support for anthropogenically forced 20th century warming trends in the tropics and other regions. In Knutson et al., the simulations where anthropogenic and natural forcing agents were evaluated separately indicated significantly closer agreement with observed trends over much of the tropical oceans in the anthropogenic forcing runs than in the natural forcing or internal climate variability runs. The anthropogenic forcings in these experiments included changes in well-mixed greenhouse gases, ozone, and aerosols, as well as land use change, whereas natural forcings included solar variations and aerosols from volcanic eruptions.

For the tropical North Atlantic, the roles of naturally occurring oscillations versus radiative forcing variability and trends on tropical Atlantic SSTs have also been evaluated using statistical modeling approaches. Goldenberg et al. (2001) proposed that a naturally occurring oscillation of the climate system, termed the Atlantic Multidecadal Oscillation (AMO), was responsible for pronounced multidecadal variations in Atlantic major hurricane counts since the 1940s. They noted that major hurricane counts covaried with fluctuations in both an AMO index derived from detrended SST data and with vertical wind shear in the Main Development Region (MDR, a term they used to describe the tropical Atlantic and Caribbean Sea region between $10^{\circ}$ and $20^{\circ} \mathrm{N}$ ). Mann and Emanuel (2006) suggested an alternative interpretation by noting that late summer SSTs in the Atlantic MDR closely track, on long time scales, surface temperatures averaged over the entire Northern Hemisphere, with substantial warming over the 20th century. Using a statistical modeling approach, they suggested that most of the low-frequency (multidecadal) variation and warming trend in MDR SSTs had been produced by changing radiative forcing, as opposed to being part of a naturally occurring oscillation. They showed, using a statistical regression approach, that the evolution of summertime tropical North Atlantic sea surface temperature through the 20th century can be represented as a combination of global mean surface temperature and sulfate aerosol forcing, which is concentrated mostly in the northern hemisphere. In general, the climate forcing from aerosols, including their indirect effects via clouds and precipitation processes, is much more uncertain than the forcing due to increasing greenhouse gases (e.g., IPCC 2007).

In another statistical analysis, Trenberth and Shea (2006) show that the method of construction of AMO indices can have a significant impact on AMO anomaly values for various time periods. They proposed that the index be constructed as a residual after removal of a nearglobal (60 N-60S) SST component, as opposed to residual from a linear trend (as in Goldenberg et al., 2001). Using this approach, they derive a revised AMO index with smoothed anomaly values of about $\pm 0.2^{\circ} \mathrm{C}$ and a transition from negative to positive values in the mid 1990s. However, the contribution of their low-pass filtered AMO anomalies to the record summer of 2005 values is quite small $\left(<0.1^{\circ} \mathrm{C}\right)$, and the anomalies from 1870 to 1900, are also much smaller (closer to zero) compared to those using the method of Goldenberg et al. In removing the global or near-global mean SST from the Atlantic SST series, both Mann and Emanuel (2006) and Trenberth and Shea (2006) include the Atlantic SST in their computation of the global or near-global mean. As can be inferred from Mann and Emanuel, this procedure could have the effect of slightly artificially damping the AMO amplitude because if there were SSTs variations in the Atlantic due to the AMO that also contribute to the global mean fluctuations, those would be partially damped as a consequence of removing the global mean variations.

Enfield and Mestas Nuñez (2000) have previously published a means of deriving an "Atlantic Multidecadal Mode" based not on linear trend removal, but on a complex empirical orthogonal function (CEOF) decomposition, in which a "Global Warming Mode" is distinguished from the Atlantic Multidecadal and Pacific interdecadal modes based on the CEOF modal 
decomposition. In their analysis the AMO is the third CEOF in a dataset from which an ENSOrelated CEOF had previously been removed (i.e., in practical terms, the AMO is their fourth CEOF). It should be noted that different SST reconstructions have been used by various investigators, which may also contribute to differences seen in the resulting analyses (e.g., Santer et al., 2006).

The existence of a robust AMO-like internal mode of the climate system is supported by some climate models, which simulate internal modes of variability that resemble the observed EOFs in several respects (Delworth and Mann, 2000; Knight et al., 2005). Zhang et al. (2007) construct a synthetic multidecadal AMO-like change in an idealized coupled climate model and show that the Atlantic Ocean, when forced to have such a multidecadal variation, can modulate northern hemisphere mean temperature. They argue that it is plausible to interpret the long-term northern hemisphere mean temperature deviations, apart from the long-term trend, as due to either radiative forcing or to an AMO-like internal variation in ocean heat transport. Zhang (2007) presents some tentative evidence for the latter interpretation, based on the covariation of Atlantic Ocean surface and subsurface temperatures in observations and models. Model based studies also indicate that such multidecadal variations of Atlantic SSTs can have important impacts on vertical wind shear in the Atlantic MDR (Vitart and Anderson, 2001; Zhang and Delworth, 2006; Knight et al., 2006), which Goldenberg et al. (2001) proposed can then affect Atlantic hurricane activity. Knaff (1997) described the physical mechanisms that relate vertical shear, SSTs, and sea level pressures in the Atlantic MDR. A recent review of the AMO-like variability in the Atlantic region is given in Delworth et al. (2007).

Enfield and Cid-Serrano (2008) also attempt to separate a global warming signal and an AMO signal in the data. Unlike the Goldenberg et al. (2001) approach, they first approximate the global warming signal not as a linear trend, but as a quadratic fit which better matches the increased rate of warming in recent years. This approach does not neglect AMO influences in basins outside of the Atlantic and does not dampen the AMO amplitude by not accounting for the Atlantic's contribution toward the global anomalies. Their results suggest that similar magnitudes are present for both the global warming and AMO in the Atlantic SSTs.

Santer et al. (2006) also provide indirect evidence that the observed low frequency variability of tropical Atlantic SST may include a substantial contribution from internal climate variability. They note that most of the 22 CMIP3 (Coupled Model Intercomparison Project 3) models they examined underestimated tropical Atlantic decadal SST variability, with average errors on the order of 50\%; the Northwest Pacific was more realistically depicted. Note that some, but not all, of these models were run with indirect effects of anthropogenic aerosol forcing and/or with volcanic forcing.

Kossin and Vimont (2007) proposed that another mode of Atlantic variability, termed the Atlantic Meridional Mode (AMM), was robust in observed data and was correlated with systematic shifts in Atlantic tropical cyclogenesis regions and several measures of hurricane activity. The AMM is an apparent coupled ocean-atmosphere mode of variability that is strongly present in the tropical Atlantic and characterized by time-varying meridional SST gradients near the equator, cross-equatorial wind variability, and north-south displacements of the Intertropical Convergence Zone (ITCZ). Spatial patterns similar to those for the AMM, as derived from observed fields, also arise as normal modes of an idealized coupled dynamical system representing a tropical atmospheric boundary layer coupled to a motionless "slab" ocean. Kossin and Vimont propose that the AMO affects Atlantic hurricanes mainly though its excitation of the AMM. Wang et al. (2008) suggest the AMO influences Atlantic hurricanes 
through modulation of the Atlantic Warm Pool (Gulf of Mexico, Caribbean Sea and western tropical North Atlantic). In a study of largescale atmospheric circulation indices, Bell and Chelliah (2006) have statistically linked multidecadal changes in Atlantic hurricane activity to a series of large-scale circulation features, all correlated to a multi-decadal circulation signal derived from empirical orthogonal function (EOF) analysis of upper tropospheric velocity potential. The indices of Bell and Chelliah's modes and Goldenberg et al.'s (2001) index of Atlantic MDR vertical shear are of insufficient length to determine whether they have a cyclical or trend-like character, and the historical changes in these indices have not yet been formally attributed to internal variability or forced variability of the climate system or a combination of the two.

Wang and Lee (2008) show that from 1949 to 2006 wind shear in the MDR was positively correlated with a "global warming mode" derived from EOF analysis of global SST, although they did not attempt to attribute the warming mode to radiative forcing or internal climate variability. They argue that a weak (nonsignificant) secular decrease in U.S. landfalling hurricanes since the mid 1800s has been, at least since 1950, associated with increasing tropospheric vertical wind shear in the tropical Atlantic Main Development Region, as inferred from NCEP Reanalysis data. One source of uncertainty not explicitly examined by Wang and Lee is the possible impact of changing observing practices and capabilities on the long-term wind shear statistics (e.g., trends) in the NCEP reanalysis data. This could be an important topic area for follow-on study.

Saunders and Lea (2005) and Elsner et al. (2000; 2006) find statistical links between U.S. landfalling hurricane activity and large-scale circulation anomalies, although long-term climate trends in their predictors have not been firmly established. Elsner and Jagger (2008) report a significant statistical relationship between U.S. and Caribbean hurricane activity and solar activity as inferred from sunspot numbers.

Using a partial correlation statistical analysis, Elsner et al. (2006) examined the relationships between global temperature, tropical Atlantic SST, and an Atlantic Power Dissipation Index (PDI, see section 3.1) on high-frequency interannual time scales. They concluded that the positive influence of global temperature on PDI was limited to an indirect connection through the tropical Atlantic SSTs. After controlling for the effect of tropical Atlantic SSTs on PDI, the correlation of PDI with global temperatures was slightly negative. This result was consistent with idealized modeling studies (Shen et al., 2000) and with statistical analyses of ENSO-Atlantic TC relationships (Tang and Neelin, 2004), both indicating inhibiting effects of tropospheric stabilization on TC intensity or frequency. Elsner (2006, 2007) uses Granger causality statistical analysis to demonstrate that global mean temperature can be used to predict North Atlantic SST but not the other way around. This, he argues, supports the hypothesis that greenhouse gases are the causal forcing agent for global temperatures and thus for North Atlantic SSTs and hurricanes. To eliminate nonstationarity in the data, as is required by the method, Elsner time differences both the global temperature and North Atlantic SST series before performing the causality tests. Since time differencing acts as a high-pass filter on the data, his conclusions about Granger causality strictly apply only to the higher frequency fluctuations that remain in the data and not necessarily to multidecadal time scales variability and trends.

Saunders and Lea (2008) use a multiple linear regression analysis to attempt to identify the relative roles of sea surface warming and atmospheric winds on the recent increase in Atlantic hurricane activity. While they find that both factors contribute substantially, they did not attempt to identify whether greenhouse warming in particular contributed to the hurricane activity increase. 


\subsection{Tropospheric Water Vapor and Temperature Trends}

Hurricane modeling studies (Shen et al., 2000) and theory (Emanuel, 1987; Holland, 1997) indicate that hurricane maximum intensities are sensitive to atmospheric temperature conditions in addition to SSTs, and modeling studies (section 6.3.1) suggest that enhanced lower tropospheric water vapor associated with climate warming can lead to enhanced rainfall rates in TCs. Therefore, in this section, we discuss evidence for secular changes in tropical atmospheric temperatures and lower tropospheric moisture and their possible causes.

Trenberth et al. (2005) have reported a substantial increase $(1.3 \% \pm 0.3 \%$ per decade $)$ in column-integrated atmospheric water vapor over the global oceans (1988 to 2003) as derived from the special sensor microwave imager (SSM/I) satellite data set (see also Soden et al., 2005). Thus, it appears that tropical precipitable water vapor is increasing in a manner consistent with the notion of approximately constant tropical mean relative humidity, and in accord with model simulations of tropical mean relative humidity under warming conditions (e.g., Knutson and Tuleya, 2004, although Vecchi and Soden (2007b) show examples of projected non-uniform regional-scale changes in tropical $700 \mathrm{hPa}$ relative humidity). Despite the relatively short available record, Santer et al. (2007) find preliminary evidence, from a formal detection/attribution analysis, that the signal of an anthropogenically driven increase in atmospheric moisture content is already emerging.

The vertical profile of historical tropospheric temperature trends in the tropics has been a subject of considerable debate and discussion in the climate change community. For example, CCSP (2006) reports that while tropical surface temperatures (land and ocean combined) have increased about $0.13^{\circ} \mathrm{C}$ per decade since 1979 , two radiosonde-based and three satellite-based data sets give a range of tropospheric temperature increases of about $0.02^{\circ} \mathrm{C}$ to $0.19^{\circ} \mathrm{C}$.
Santer et al. (2005) examined the profile of temperature changes for the period 1979-1999 produced by a large ensemble of climate models, all incorporating a range of historical forcings including greenhouse gases and aerosols, with some of the models incorporating volcanic eruptions. The climate models generally simulate an enhanced warming of the tropical upper troposphere relative to the surface, roughly approximating the behavior of moist adiabatic lapse rates. In contrast, the observed vertical profiles of radiosonde-derived atmospheric temperature trends (and some satellite-derived trends) over this period have a distinctly different character from the model simulations, with the tropospheric warming trends that are comparable to or smaller than those at the surface. Finally, Santer et al. showed that both models and observations have interannual variations in upper tropospheric temperatures that are enhanced relative to the surface variations. Thus the vertical structure of interannual variations is similar to that of modeled trends (1979-1999), but is in sharp contrast with the vertical structure of observed trends (1979-1999) in tropical tropospheric temperatures. Their results are suggestive of serious remaining problems with radiosonde-derived and/or satellite-derived temperature trends a conclusion also receiving some support from other recent studies which examined issues with radiosonde-based observations (Sherwood et al., 2005) and satellite-based analyses (Fu et al., 2004; Mears and Wentz, 2005). CCSP (2006) concluded that it was very likely that errors remain in adjusted radiosonde data sets in the troposphere, and that for satellite data, differences in data merging procedures were the main cause of discrepancies in tropospheric temperature trends among those data sets.

The possibility that tropospheric trend estimates from radiosonde-based observations, satellites, and reanalyses may be unreliable should be considered as a caveat when reviewing other published reports on related trend 
measures. Other thermodynamic measures of tropical climate relevant to hurricane formation which have been examined for possible trends include CAPE and potential intensity. For example, Gettleman et al. (2002) found a preponderance of upward trends in tropical CAPE since roughly the early 1960s. DeMott and Randall (2004) examined a larger number of tropical stations over a shorter period (19731999) and reported a more evenly divided mixture of increasing and decreasing CAPE trends. Trenberth (2005) questioned the reliability of the radiosonde data in DeMott and Randall's larger sample. Free et al. (2004), using a selected set of 14 tropical island radiosonde stations, found only small, statistically insignificant trends in potential intensity over the periods 1975 to 1995 and 1980 to 1995 . Emanuel (2007a) reported a 10\% increase in Atlantic MDR potential intensity since 1982 based on HadISST and NCEP reanalysis data.

\subsection{Other Sources of Long-Term Variability in Tropical Cyclone Activity}

Other climate variations that have been statistically linked to variations in Atlantic hurricane activity include West African monsoon activity and El Niño (e.g., Gray, 1990; Bell and Chelliah, 2006), and African dust air outbreaks (Evan et al., 2006). Therefore, long-term variations in their behavior, whether anthropogenic or natural in origin, could lead to long-term variability in Atlantic hurricane activity.

Several studies (Rotstayn and Lohmann, 2002; Held et al., 2005; Biasutti and Giannini, 2006) have found that 20th century trends in Sahel rainfall may have been at least partially forced by anthropogenic forcing, albeit through different physical mechanisms. In Rotstayn and Lohmann's study, anthropogenic indirect aerosol forcing, through the interaction of sulfate aerosol with cloud and precipitation processes, causes a pronounced decrease in rainfall in the Sahel. In Held et al. (2005) the Sahel drying from the 1950s to the 1980 s is simulated by models forced by observed SST variations, and in terms of casual mechanisms, their model results suggest approximately equal contributions of internal climate variability and radiative forcing to the drying trend. The radiative forcing in the model was primarily anthropogenic "direct effect-only" aerosol forcing and increasing greenhouse gases). Biasutti and Giannini (2006) analyzed a large sample of IPCC AR4 models and found a more robust decrease in Sahel rainfall in response to late 20th century aerosol forcing, estimated at roughly one-third of the observed decline. In contrast, they found no consensus among the models on whether greenhouse warming alone contributed to late 20th century Sahel drying. Thus conceivably, human activities could have influenced Atlantic hurricane activity through their effects on Sahel rainfall.

The notion that outbreaks of dry, dust layers from the Sahara could affect Atlantic hurricane activity was hypothesized by Dunion and Velden (2004). In support of this mechanism, Evan et al. (2006) find a strong statistical relationship between atmospheric dust episodes over the Atlantic tropical storm regions and measures of Atlantic tropical cyclone activity during 19822005. This statistical connection conceivably could reflect a system in which both a drier Sahel and Atlantic TCs are influenced by a common factor: SST gradients in the Atlantic region.

Concerning the influence of El Nino, Vecchi et al. (2006) report evidence for a weakening trend in the Walker Circulation in the Pacific during the 20th century, similar to that which occurs during El Niño, and consistent with hindcast predictions by a number of climate models. Whether this has had any impact on Atlantic hurricane activity through remote influences remains unclear. As tentative evidence of a possible link, Wang and Lee (2008) report a statistical association between increasing vertical wind shear in the tropical Atlantic since 1949 and a global warming SST mode, along with a further statistical link to a slight decrease 
in U.S. landfalling hurricane activity. Vecchi et al. (2008) review the current status of the debate over whether greenhouse warming will lead to a more El Nino-like or more La Nina-like mean state in the tropical Pacific. The answers to this debate have important implications for future tropical cyclone activity. Merryfield (2006) reports no conclusive consensus from current (CMIP3) models on whether El Nino variability will increase, decrease, or remain essentially unchanged with future greenhouse warming.

In the Southern Hemisphere, observed trends in the Southern Annular Mode have been at least partly attributed to anthropogenic forcing (Marshall et al., 2004). Pezza and Simmonds (2005), commenting on the rare atmospheric conditions associated with the first reported hurricane in the South Atlantic (Catarina, 2004), suggested that observed and predicted trends in the Southern Annular Mode could increase the probability of such conditions in the future.

The Southern Annular Mode, Pacific Walker circulation, Sahel drought, and African dust studies cited above serve as reminders that the relationship between radiative climate forcing and hurricane response may involve a variety of complex tropics-wide or even global-scale phenomena.

\section{Observed Trends and \\ Low-Frequency Variability of Tropical Cyclone Activity}

Much of the recent increased attention of the hurricane research community to historical tropical cyclone records has been sparked by two observational studies of low-frequency variability and trends in several measures of tropical cyclone activity (Emanuel, 2005a; Webster et al., 2005), and the follow-on studies by these and other investigators. These are reviewed according to several general topic areas that have emerged.

\subsection{Atlantic Basin Storm Intensities and Power Dissipation}

Emanuel (2005a) developed a "Power Dissipation Index" (PDI) of tropical cyclones, based on the time integrated cube of the estimated maximum sustained surface wind speeds, some of which are inferred from central pressure reports, for the Atlantic and Northwest Pacific tropical cyclone basins from the late 1940s to 2003. After adjusting for time-dependent biases due to changes in measurement and reporting practices, Emanuel reported an approximate doubling of the PDI over the period of record, with contributions from apparent increases in both intensity and mean storm duration. The two low-pass filtered PDI series in his study were significantly correlated with large-scale tropical SST indices in both basins. Landsea (2005) noted that much of the large post-2000 upswing in Emanuel's (2005) Atlantic PDI results from a problem with the treatment of endpoints from time filter used. He also noted that there is no evidence for a trend from 1949-2004 similar to published time series of major hurricane counts or Accumulated Cyclone Energy (ACE, Bell and Chelliah 2006) - provided that wind speeds early in the record are not adjusted downward, as had been originally proposed by Landsea (1993).

More recently, Emanuel (2007a) provided additional evidence supporting the need for a downward adjustment of intensities in the early part of the record, based on available combined wind-pressure measurements, and in agreement with Landsea's (1993) earlier analysis. Emanuel's (2007a) revised analysis (Fig. 1, updated through 2007) shows that both tropical Atlantic SST and PDI increased substantially between the $\sim 1950$ and 2005 , and that their low-pass-filtered variations are wellcorrelated, particularly from $1970 \mathrm{on}$. Landsea (2005) has argued that PDI values from the $1940 \mathrm{~s}$ to the $1960 \mathrm{~s}$ in the HURDAT database are likely to be substantially biased 


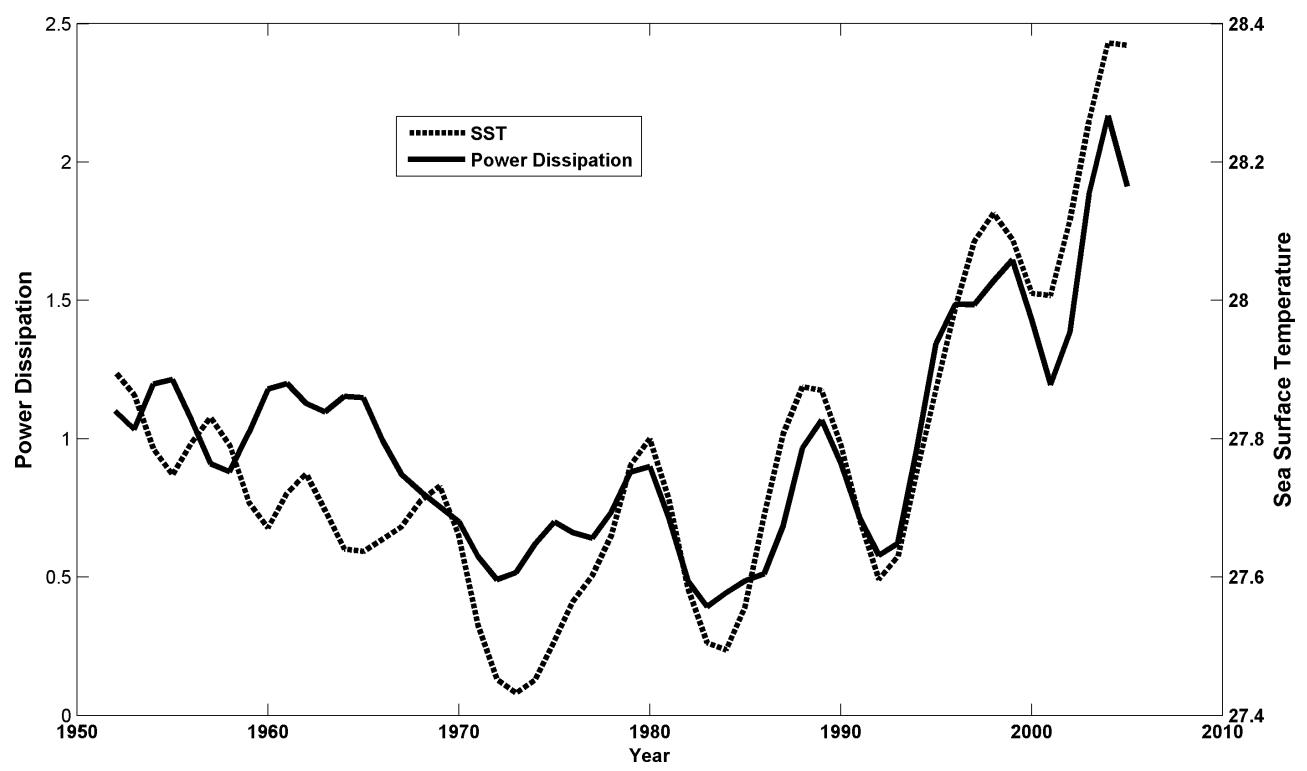

Figure 1. Low-pass filtered tropical Atlantic sea surface temperature (dashed) correlated with the Power Dissipation Index (solid) for North Atlantic hurricanes (Emanuel, 2007a; data updated through 2007). SST is averaged over $6^{\circ}-$ $18^{\circ} \mathrm{N}, 20^{\circ} 60^{\circ} \mathrm{W}$, Aug.-Oct. The data for 1949 to 1969 are bias-adjusted to correct for a high bias in HURDAT's winds (Landsea, 1993). No adjustments are made to account for incomplete sampling of tropical cyclone frequency (Vecchi and Knutson, 2008), duration or intensity, which may adjust the earlier part of the record toward higher values of PDI.

low due to lack of routine aircraft reconnaissance far from land and no geostationary satellite monitoring of TCs. Emanuel (2007a) attributes the near doubling in Atlantic PDI during the past 25 yr to decreasing shear early in the period and increasing low-level vorticity and potential intensity over the entire period. He further attributed the $10 \%$ increase in potential intensity over the period mainly to increasing net radiative fluxes into the ocean and decreasing tropopause temperature, with SST as a cofactor, rather than a primary cause. Swanson (2008) provides an alternative perspective on statistical correlations between Atlantic PDI and SST, showing that an alternative SST index (tropical Atlantic SST minus tropical mean SST) correlates with Atlantic PDI just as well, if not better, than does local tropical Atlantic (MDR) SST. He argues that there is no straightforward statistical link between warmer SSTs in the MDR and more intense Atlantic tropical cyclone activity.
A U.S. landfalling PDI series (Landsea, 2005; updated to 2009 in Fig. 2) shows no evidence for a long-term trend since 1900 in U.S. hurricane landfalling activity. PDI for 2004 and 2005 were strong positive outliers, but a similar magnitude PDI was estimated for 1886. Emanuel (2005b) notes that a PDI series such as Landsea's (2005) based on only U.S. landfalling data, contains only about 1 percent of the data that Emanuel's (2005a) PDI contains, which is based on all storms over their entire lifetimes. Thus a trend in basin-wide PDI may not be detectable in U.S.

landfalling PDI since the former index has considerable advantage in signal to noise ratio. However, it has been previously shown that U.S. hurricane strike variability shows up robustly in both interannual forcing by El Nino-Southern Oscillation (Bove et al., 1998) and AMO variability (Goldenberg et al., 2001).

Using a statistical modeling approach, Briggs (2008) examined the time varying behavior of PDI of individual storms and its components. He examined three time periods 


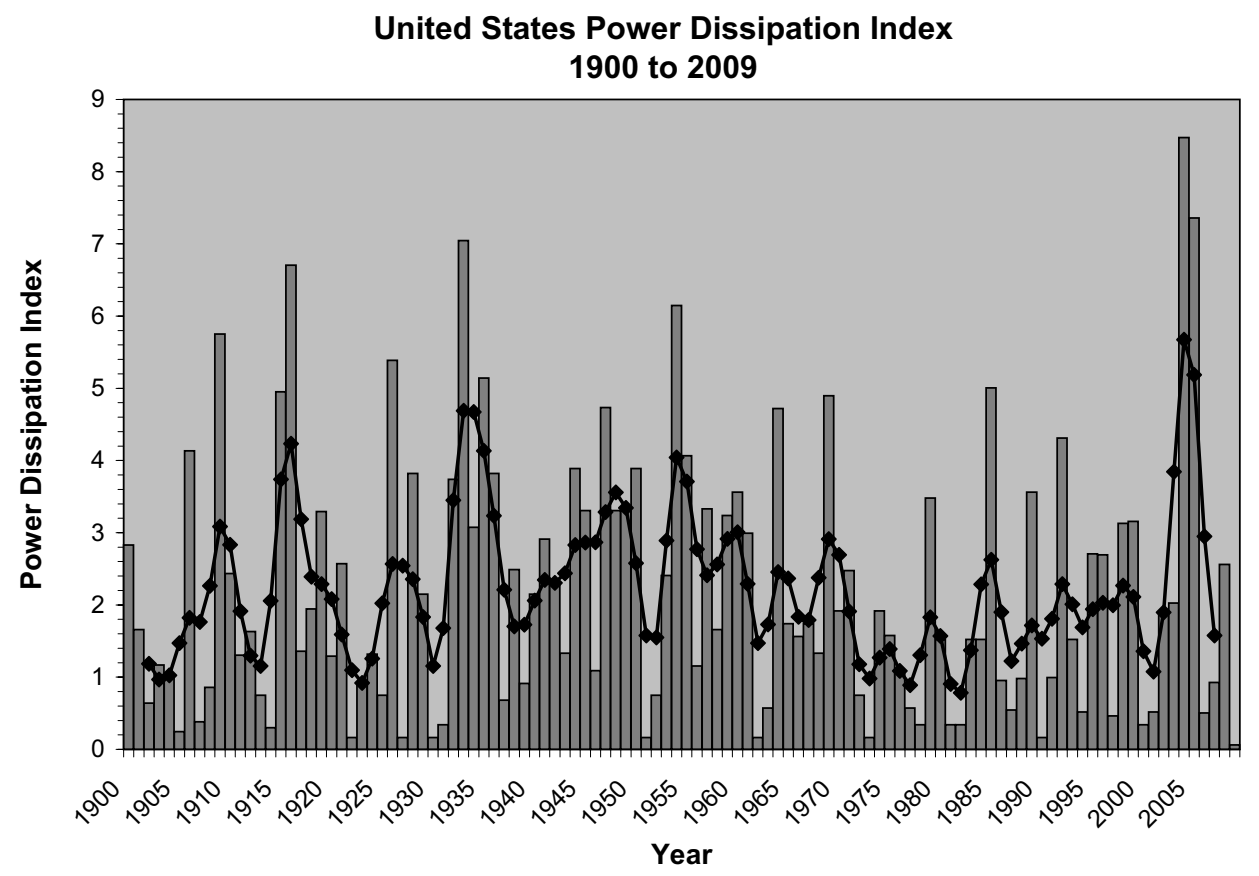

Figure 2. U.S. Power Dissipation Index at the time of impact for tropical storms, subtropical storms, and hurricanes impacting the U.S. for years 1900-2009, updated from Landsea (2005). Black line is the five-year running mean. No adjustments are made to account for incomplete sampling of tropical cyclone frequency and intensity (duration has no component for this analysis), though it is not likely that significant errors due to sub-sampling exist since about 1900 (Landsea, 2005).

(1900-2006, 1966-2006, and 1975-2006) for the Atlantic basin, with varying levels of confidence in the underlying data for these periods. Results were generally dependent on start date, but he found evidence that in recent decades the variance of both PDI and of intensity of individual storms has increased, indicating that storms have had a greater range of maximum wind speeds in more recent years, though their mean intensity has remained unchanged. Elsner et al. (2008) report an increase in mean Atlantic TC intensities over 1981-2007, but also find, similar to Briggs (2008), that the largest increases occurred for the more intense hurricanes. Wu et al. (2008) report that average Atlantic TC intensities changed little over 19752004 , while the number and duration of storms has increased. Emanuel (2007a) discusses difficulties with attributing PDI changes to various factors, noting that there is no unique method for deconvolving PDI into different component contributions.

Elsner et al. (2006) and Jagger and Elsner (2006) use a data modeling approach to examine historical hurricane intensities in the U.S. coastal region, including the statistical relationship of intense hurricanes with climate phenomena such as El Nino, the Atlantic Multidecadal Oscillation (AMO), and global mean temperature. Their data model finds that during warm global mean temperature years, the maximum surface wind speeds of extreme storms are higher than in cool global mean temperature years. Their model predicts an $11 \%$ increase in the maximum surface wind speeds of a 100-yr return period storm for warm vs cool global mean temperature years. However, Jagger and Elsner (2006) note that the AMO and global mean temperature series are correlated at $r=0.79$, and AMO is not controlled for 
in their regression with global temperature, so the relationship of their findings to greenhouse gas induced global warming is not presently clear. The sense of dependence they find is at least qualitatively consistent with theoretical and modeling studies of the impact of greenhouse warming on hurricane intensities (sections 6.1.2, 6.2).

Manning and Hart (2007) document how Atlantic tropical cyclones of known categories have changed over time in the ECMWF (European Centre for Medium-range Weather Forecasts) reanalysis. They find that hurricanes in the last two decades are much better resolved (more substantial warm core, deeper pressure) than the same category hurricane in the 1950 s to $1970 \mathrm{~s}$. However, even in the last 15 years, Category 4 and 5 hurricanes in the ERA40 (ECMWF 40-Year Re-analysis) have central pressures only a few HPa lower than Category 1 hurricanes (1000 vs. $1005 \mathrm{HPa})$. Such improved representation makes finding real climate trends in TC mesoscale quantities like maximum wind/central pressure using reanalysis output very problematic, at best.

\subsection{Atlantic Basin Tropical Cyclone Counts}

Several studies have attempted to look at longer tropical cyclone records in the Atlantic by concentrating on storm counts. This requires knowing that a storm existed, and whether the storm exceeded certain intensity thresholds (e.g., tropical storm, hurricane intensity) at any point in its lifetime as a tropical cyclone. In contrast, the PDI is based on intensity information over entire lifetimes of storms, and thus studies of basin-wide PDI have generally been restricted to the aircraft reconnaissance era $(\sim 1946$ and later). Mann and Emanuel (2006) pointed out that the existing record of annual counts of tropical cyclones for the Atlantic basin had a long term upward trend, and after low-pass filtering, was correlated with a similar rise in tropical Atlantic SST since 1871. Mann and
Emanuel (2006) argue that detection of the existence of TCs in the years prior to the 1940s was less problematic than TC intensity estimates, since in the absence of aircraft and satellites based guidance to warn them of approaching storms, ships often encountered TCs at sea, at least peripherally.

Holland and Webster (2007) also concluded that Atlantic tropical storm counts had increased substantially, with over a $100 \%$ increasing trend in annual numbers of tropical cyclones and of hurricanes over the past 100 years, which they attributed to greenhouse warming. They interpreted the covarying behavior of tropical cyclones and SSTs during the past century in terms of three relatively stable regime periods lasting several decades each, separated by sharp transitions between regimes. While the proportion of storms becoming major hurricanes appears to have a multidecadal variation, they noted that there was no long-term trend in this proportion measure. Since they had found a long-term rising trend in tropical cyclone numbers, they concluded that major hurricanes also had an increasing trend similar to that for all tropical cyclones. In contrast to storm numbers, they report that there has been no distinct trend in the mean intensity of all Atlantic tropical storms, hurricanes, or major hurricanes.

The above studies assumed that tropical storm counts in the historical record, back to 1900 or into the late 1800 s, were not systematically biased low (or high) in the earlier years. A number of other studies conclude that a low storm count bias exists in earlier parts of the record. In early work on this topic, FernandezPartagas and Diaz (1996) estimated an average annual storm count (June-October season) of 8.5 for the period $1851-1890$ as opposed to 7.5 in the observed record. They use the fraction of tropical storms making landfall to adjust the basin-wide numbers, which assumes that all tropical storms making landfall have been accurately counted. Solow and Moore (2002) found no evidence for a trend in Atlantic hurricane 
activity (1900-98). Their statistical analysis assumed that the record of hurricanes making U.S. landfall is complete over that period and that the probability that a hurricane made landfall in the U.S. was constant over their period of analysis. Landsea et al. (2004) estimated the number of "missed" Atlantic basin tropical storms and hurricanes per year to be on the order of $0-6$ for the period $1851-85$ and $0-4$ for the period 1886-1910. They argued that the TC record over the Atlantic should by no means be considered complete for either frequency or intensity of tropical storms and hurricanes for the years 1851 to 1910 , in contrast to the more complete and accurate information available for landfalling TCs along much of the U.S. coastline.

In a more regionally focused landfalling TC study, Mock (2004) analyzed records of TC activity from 1769 to 2003 for the state of South Carolina in an effort to assess a relatively homogeneous multi-century record of tropical storm and hurricane strikes. This analysis suggests pronounced multidecadal variability, but no long-term trends. Given the well-established communities along the South Carolina coastal regions since the 18th century, it is unlikely that any significant hurricanes were not captured in this record.

In response to the Mann and Emanuel (2006) study, Landsea (2007) analyzed the fraction of Atlantic tropical storms making landfall each year since 1900 and found an apparent step-function increase in this fraction corresponding to the advent of satellite reconnaissance in 1966. (Landsea (2007) began his analysis in 1900, based upon the assumption that nearly all landfalling tropical cyclones would be reliably monitored from that year forward because of increased coastal populations by that time [Landsea et al., 2004], and assumed that the fraction of storms making landfall over 1966-2006 was representative of the long-term average.) Using that fraction, he thus proposed to adjust the pre-satellite era basin-wide storm counts (1900-1965) upward by 3.2 storms per year for 1900-1965 and 1.0 storms per year for 1966 to 2002 . He proposed that in the years 2003 and later, improved observational sources and analysis methods have led to the identification of about one additional storm per year since 2003 . Landsea's (2007) assumption of a constant longterm fraction of landfalling tropical storms was disputed by Holland (2007) who reported that the fraction of storms making landfall was also low during periods of the 19th century, when no satellites were available. Mann et al. (2007) use a statistical reconstruction of storm counts based on a combination of climate indices to infer a smaller "missing storm" adjustment than Landsea (2007), specifically a range of 0.5 to 2 storms per year, most likely value of 1.2 , for the years 1870-1943.

Two independent groups (Chang and Guo, 2007; Vecchi and Knutson, 2008) have attempted to estimate past numbers of missing Atlantic tropical storms using historical ship track records, since identification of storms that did not make landfall prior to aircraft and satellite reconnaissance depended on reports from ships of opportunity. The estimated number of missing storms is quite similar between these two studies, at least for periods of the 20th century that the two studies have in common ( 0.2 to 1.2 storms per year from the early 1900 s to 1965 , except the two world war periods). Vecchi and Knutson estimated larger adjustments (roughly 2 to 3 storms per year) for the two world war periods and from 1900 back to 1878 . The tropical storm count series using their "base case" adjustment was estimated to contain a statistically significant positive trend over the period 1900-2006, but the higher activity levels in the late 19th century, coupled with their larger adjustment for that period, resulted in a statistically insignificant $(p=0.05)$, nominally positive trend for the period 1878-2006.

An assumption common to both the Chang and Guo (2007) and Vecchi and Knutson (2008) analyses is that any tropical cyclone of tropical storm intensity or greater in the COADS ship data would have already been included into HURDAT. Unfortunately, COADS has not yet been utilized for the reassessment of HURDAT for the period of 1851 to 1910 (Landsea et al., 
2004). The ship database has recently been incorporated into the reanalyses that have been completed for 1911 to 1920 (Landsea et al. 2008). This reanalysis using the COADS data and other sources have resulted in the addition of 13 previously unidentified tropical cyclones for the period 1911-1920. (There was also one tropical cyclone removed from HURDAT because the criteria for identifying a tropical cyclone by today's standards were not met.) Thus an additional 1.2 tropical cyclones per year in the early 20th Century should be added to the numbers estimated to be missing by Chang and Guo (2007) and 0.7 TCs per year to the estimates of Vecchi and Knutson (2008), as the latter study already includes five of the 12 (net) recently added storms in HURDAT. Chang and Guo (2007) also assumed that only one observation of gale force winds was needed for a tropical storm to be included in HURDAT. As documented by Landsea et al. (2008), two independent observations are required for such inclusion in practice. As shown by Vecchi and Knutson (2008), using two versus one observation, as has been done for HURDAT, results in a small, but meaningful increase in the estimate of missing tropical cyclones.

Solow and Beet (2008) expand on the Mann et al. (2007) statistical reconstruction mentioned previously, using a statistical model with MDR SST and the Southern Oscillation Index (SOI) as predictors of annual Atlantic tropical storm counts. In an innovation from previous work, their Poisson distribution-based model allows for a probability of observing storms which can decrease (but not increase) as one goes back in time. With this approach, they find that additional evidence that the existing Atlantic tropical storm count record is not complete for the years 1870-1966. They also infer a significant positive sensitivity of Atlantic tropical storm counts to MDR SST, with an increase of $50 \%$ (95\% confidence interval of about $+23 \%$ to $+84 \%$ ) for the roughly $0.8^{\circ} \mathrm{C}$ rise in MDR SST since 1870.

As noted in CCSP (2008), time series of hurricane counts (with no adjustments for possible inhomogeneities like those just discussed for tropical storms) have a significant positive trend over some analysis periods, (e.g., beginning in years 1881 through 1921 and in each case ending in 2005), whereas the trends from the earlier periods (beginning in 1851 through 1871) are not statistically significant. Elsner et al. (2004), Wang and Lee (2008) and Vecchi and Knutson (2008) find that there is no evidence for significant long-term trends in U.S. landfalling hurricane frequency. The unadjusted series for basin-wide major hurricane counts has significant positive trends beginning from 1901 and 1911 (CCSP, 2008). Holland and Webster (2007) find that the relative occurrence of major hurricanes and hurricanes as a proportion of the total number of Atlantic tropical storms has remained fairly stable (with no trend) going back to around 1900. They argue that this lends support to the notion of a true increase in hurricane and major hurricane counts since 1900 based on the increases in tropical storm counts since then. However, the lack of significant tropical storm trends from 1878 to recent years as reported in Vecchi and Knutson (2008) would lend support to the finding of no significant increase in hurricanes and major hurricanes since 1878. Furthermore, the impact of missing storms or underestimated intensities on the hurricane and major hurricane trend results has not yet been assessed using, for example, the methodologies applied to tropical storm counts.

Focusing on the very recent period (19832005) when a relatively homogeneous record of intensities is obtainable from infrared satellite imagery, Kossin et al. (2007) confirmed that there has been a recent increase in the number of percentage of very intense hurricanes in the Atlantic. This study is discussed in more detail in Section 3.5.

\subsection{Northwest Pacific Tropical Cyclone Analyses}

Emanuel (2005a) reported a strong increase in PDI accumulated over the Northwest Pacific and Atlantic basins, estimating that PDI had 
doubled over the past 30 years. The PDI increase generally accompanied the observed long-term rise in tropical and Northwest Pacific SST, similar to the behavior found for the Atlantic. However, in the Northwest Pacific, the correlation between PDI and SST on time scales of more than a few years, although still present, was weaker than found for the Atlantic. Emanuel (2007a) presented a revised version of the Northwest Pacific PDI and SST, with some further corrections for missing storms, including use of adjusted data from Kossin et al. (2007). Wu et al. (2008) attribute an increase in Northwest Pacific PDI over 1975-2004 mainly to an increase in average intensity, although Emanuel (2007a) reports some sensitivity of such results to details of the method used to deconvolve PDI into contributing factors.

Chan (2006) extended the analysis of Webster et al. (2005), discussed below, for the Northwest Pacific basin back to earlier years and argued that the "trend" in that basin is part of a large interdecadal variation (see also Webster et al., 2006; Chan and Liu, 2004). Chan used unadjusted data from the earlier part of the record, in contrast to the adjustments for this period proposed by Emanuel (2005a) for the basin. Using observations from the U.S. Joint Typhoon Warning Center (JTWC), Chan (2007) concludes that the multi-decadal variations in intense typhoon occurrence in the Northwest Pacific for the period 1960-2005 have been driven mainly by the influence of El Nino and Pacific Decadal Oscillation (PDO) variability on large-scale atmospheric conditions. He does not find an attributable effect of global warming on the typhoon activity.

Kamahori et al. (2006) examine how the records of typhoon days compare between the Japanese Meteorological Agency (JMA) typhoon best tracks and those from the JTWC (which were used in Emanuel (2005a) and Webster et al. (2005)) from 1977 until 2004. They found a 15-30\% increase in TC days with an intensity of category 2 or higher in both data sets, but there were pronounced differences between the two data sources regarding the distribution of storms within the category 2-5 range. For example, they found that the number of Category 4 and 5 typhoon days decreased from 7.2 per year in $1977-90$ to 4.3 per year in 1991-2004 in the JMA database. This contrasts with the JTWC dataset, which showed for Category 4 and 5 typhoon days 9.8 per year from 1977-90 and 16.9 per year from 1991-2004.

Wu et al. (2006) analyzed the best track data from JMA as well as that of the Hong Kong Observatory (HKO) and found no evidence for a secular increase in western North Pacific category 4 and 5 typhoon frequency since the mid 1960s. Furthermore, neither JMA nor HKO best track data suggest an increase in western North Pacific tropical cyclone destructiveness as measured by the PDI. The discrepancies almost certainly relate to JMA/HKO vs. JTWC satellite treatment of TC intensities once aircraft reconnaissance was discontinued there in 1987 . There is currently no guidance as to which, if any, of these datasets is more reliable for assessing climate trends in extreme TCs, pointing to the importance of improving future monitoring of TC activity through enhanced in situ measurement such as by aircraft reconnaissance.

\subsection{Southern Hemisphere Regional Tropical Cyclone Analyses}

Kuleshov et al. (2008) focused on the southern hemisphere TC basins, and examined the TC data for linear trends over 1981/82 to 2006/06, using TC data from the Australian Bureau of Meteorology, Meteo France (La Reunion), and the Meteorological Services of New Zealand and Fiji. Pre-1981 data was excluded due to concerns about data homogeneity, whereas they considered the data from 1981 TC season on as homogeneous. They reported significant positive trends in the occurrences and number of cyclone days for "severe TCs" with central pressures of $945 \mathrm{hPa}$ or lower. They found no significant trends for all TCs in aggregate, nor for relatively 
strong TCs with central pressures of $970 \mathrm{hPa}$ or lower.

Harper et al. (2008) reported on an analysts' review of TC intensities from 1968/69 to 2000/01 in the northwest Australian TC region. According to the review, a low bias likely existed in the earlier parts of the record (mainly pre1980), which reduced trends over the period relative to those in the original data sets. The bias, in terms of central pressure deficit, was estimated as at least $20 \%$ in 1970 , about $10 \%$ by 1980 , and about $5 \%$ by 1985 . To illustrate the impact of the bias on linear trend estimates (1968-2000), their calculated linear trend in PDI from the original (Neuman) data set showed a very large increase $(\sim 80 \%)$ over the period, whereas using the review-adjusted data, the estimated PDI trend was much smaller $(\sim 10 \%$ increase).

\subsection{Global Tropical Cyclone Analyses}

Webster et al. (2005) reported that the number of category 4 and 5 hurricanes has almost doubled globally over the past three decades. Although their analysis spans a shorter time period than Emanuel's (2007a), due to their decision to limit the analysis to the satellite era, their results indicate that a substantial increase has occurred in all six tropical storm basins that they studied. They found no trend in the numbers of tropical storms and hurricanes or in the maximum wind speed observed globally each year. While they also found an increasing trend in the duration of Atlantic tropical cyclones over this period, no significant trend in duration was identified in the other tropical basins. In a follow-on study, Hoyos et al. (2006) found that the increasing trends in category 4 and 5 tropical cyclones are principally correlated with SST as opposed to other environmental factors.

Using a different approach, Sriver and Huber (2006) computed power dissipation statistics from ECMWF (ERA-40) reanalysis data from 1958 to 2001 using Best Track data to identify
TC tracks. Despite the coarse resolution of the reanalysis data $\left(1.125^{\circ}\right.$ longitude by $1.125^{\circ}$ latitude), their resulting global indices, normalized by their standard deviations, are well-correlated with Emanuel's (2005a) Atlantic + Western North Pacific PDI, particularly after 1978.

Sriver and Huber estimated a sensitivity of global power dissipation of roughly $60 \%$ per $0.25 \mathrm{deg}$ C SST increase. In comparing these sensitivities, note that PDI depends on the cube of the wind speed and includes effects of storm duration and frequency. Nonetheless, a much higher intensity sensitivity is likely implied by Sriver and Huber's analysis than was reported for example for the Atlantic basin by Michaels et al. (2006), who used a statistical analog approach (see Section 5.2). As an example, if we assume based on Emanuel (2005a) that the PDI change is half due to intensity increase and half to duration increase with no frequency change, the above sensitivity estimates still differ from each other by more than a factor of 10. Maue and Hart (2007) find that most $(80 \%)$ of the global power dissipation variance is described by the duration and frequency variability in the Best Track data set, and thus is not independent information from that contained in ECMWF reanalysis. Maue and Hart (2007) found that the correlation between $\mathrm{TC}$ winds cubed in the ECMWF (either maximum or areal averaged) versus Best Track winds cubed was only 0.3 , or about $10 \%$ of the variance. Moreover, they showed that there does not exist any trend in the $\mathrm{TC}$ winds obtained from the ECMWF reanalyses for the years of 1958 to 2001. They conclude that Sriver and Huber's (2006) finding should not be interpreted as independent confirmation of previous findings using the Best Track data. These results also suggest that reasonable empirical estimates of PDI low-frequency variability can be obtained even in the absence of good intensity data, since the PDI low-frequency variability appears to be dominated by TC frequency and duration, with the influence of intensity being secondary. 
The studies reporting strong long-term increases in multi-basin (e.g., Emanuel, 2005a, 2007a) or global tropical cyclone activity (Webster et al., 2005) have been the subject of much debate in the hurricane research community, particularly with regard to the homogeneity of the tropical cyclone data over time and the required adjustments.

Landsea et al. (2006) propose that much perhaps the majority - of the global increase in Category 4 and 5 TCs since 1970 may be due to data reliability issues since strong TCs are more accurately monitored in the more recent years. They documented six additional Category 4 and 5 TCs in the North Indian Ocean during the 1970s and 1980s, which were not counted as such in the Webster et al. (2005) study. The inclusion of these extreme TCs make the trend found in the North Indian Ocean much weaker. They argue that such systematic undercounts are endemic in the global TC records, especially in basins that rely primarily upon satellite imagery for intensity monitoring (that is, all but the Atlantic).

Over the period 1986-2005, Klotzbach (2006) finds no significant change in global net tropical cyclone activity, as described by the ACE Index, and a small trend $(\sim+10 \%)$ in category 4 and $5 \mathrm{TC}$ frequencies. He restricted his analysis to this 20-yr period owing to data quality concerns. In particular, while he finds a large increase in TC activity in the Atlantic from 1986-2005, there is a nearly commensurate decrease in the Northeast Pacific, and the remaining global basins show negligible changes in the 20-year period.

In a major advance toward creating a more globally homogeneous tropical cyclone data set for climate studies, at least for the satellite era, Kossin et al. (2007) reanalyzed tropical cyclones using a more temporally consistent algorithm and data source (infrared imagery from geostationary satellites) to estimate intensities than previous studies had used. Over their period of analysis (1983-2005), they found that their global PDI decreased slightly, in contrast to the increase estimated from the original Best
Track data. While their PDI trends agreed well with Best Track trends in the Atlantic and East Pacific basins, they were lower than the Best Track PDI trends for the same period in the remaining four basins, suggestive of temporal inhomogeneities in the Best Track. Emanuel (2007a) incorporated the Kossin et al. data into a revised analysis of PDI for the NW Pacific and reported a $35 \%$ increase since the 1970s, although the time series has much weaker correlation with low-frequency SST variability than does the PDI series for the Atlantic.

Using a modified version of the Kossin et al. (2007) TC intensity data set, Elsner et al. (2008) analyzed the lifetime maximum TC intensities globally using a quantile regression approach, exploring for possible trends in the higher intensities (upper quantiles) and possible relationships with sea surface warming. For the period 1981-2006, they reported significant upward trends for quantiles above the 70th percentile globally, with the largest increases in the North Atlantic basin. While they found some evidence for significant trends in other basins - particularly the North and South Indian Ocean basins - the evidence for significant increases in upper quantiles was much more mixed in the northwest, northeast, and southwest Pacific TC basins. Regressing maximum intensities against basin-scale seasonal-mean SST anomalies, they report a global sensitivity factor of $6.5 \pm 4.2 \mathrm{~m} \mathrm{~s}^{-1}$ (s.e.) per deg C SST rise, which is suggestive of a positive dependence although not statistically significant. The cause of the trends in intensity that they identified remains to be determined, as their analysis did not allow for an attribution of the trends to various causal factors, such as greenhouse warming.

Some regional low-frequency variability in prevailing typhoon tracks in the western North Pacific for the period 1965 to 2003 have been reported by Wu et al. (2005), although they were not able to distinguish between anthropogenic impacts or long-term natural variability. The changes in tracks were found to be consistent with expected changes based on large scale circulation (steering flow) changes. 


\section{Paleoclimate Proxy Studies of Past Tropical Cyclone Activity}

Paleotempestology is the term for an emerging field of science that attempts to reconstruct past tropical cyclone activity using geological proxy evidence. Ancient historical documents have also been used to reconstruct past tropical cyclone activity. These techniques attempt to expand knowledge about hurricane occurrence back in time beyond the limits of conventional instrumental records, which cover roughly the last 150 years. A long-term record of hurricane activity on time scales of centuries to millennia is especially important in understanding the spatial and temporal variability of the rare but most intense landfalling hurricanes. Broader goals of paleotempestology are to help researchers explore physically based linkages between prehistoric TC activity and other aspects of past climate and to help provide independent evidence for causes of changes in hurricane climate.

Among the geologically based proxies, overwash sand layers deposited in coastal lakes and marshes appear to be quite useful (e.g., Liu and Fearn, 1993, 2000; Liu, 2004; Donnelly and Webb, 2004). The storm surge plus wave run-up during an intense hurricane can overwash a beach barrier, eroding sand and depositing a layer of the eroded sand material in a lake or marsh behind the barrier. These layers can then form a stratified record through time of intense storm overwash events. Cores of these layers can be retrieved and the layers analyzed in terms of their thickness, composition, age, and frequency of occurrence. The age of deposits is estimated through various radiometric dating techniques applied to the surrounding organic matter, supplemented by other information. In interpreting such records, confounding factors (e.g., long-term changes in sea level) must also be taken into account.

A comparison of prehistoric overwash deposits with those of well-observed storms in the modern historical record allows inferences about prehistoric storm events to be made (Liu and Fearn, 1993, 2000). Similar methods have been used to produce multi-century scale proxy records of hurricane strikes from back-barrier marshes in Rhode Island, New York, and New Jersey (Donnelly et al., 2001a,b; Donnelly et al., 2004; Donnelly and Webb, 2004, Scileppi and Donnelly, 2007, and from back-barrier overwash deposits in the Caribbean (Donnelly, 2005; Donnelly and Woodruff, 2007). Deposits of anomalous graded beds in the layered sediments of a near coastal lake in the Boston area, related to intense rainfall and vegetation disturbance from hurricanes, have also been used as proxy hurricane records (Besonen et al., 2008). In the Australia region, the frequency of cyclone or "super-cyclone" occurrence over the past 5000 years has been inferred from chronostratigraphic series of shelly beach ridges (Nott and Hayne, 2001; Hayne and Chappell, 2001).

Stable isotope signals in tree rings (Miller et al., 2005), cave deposits (Frappier et al., 2007) and coral reef materials are also being actively explored for their utility in providing paleoclimate information on tropical cyclone activity. These methods attempt to exploit an oxygen isotope signal that distinguishes rain originating in hurricanes from that in low-latitude thunderstorms (Lawrence and Gedzelman, 1996). Rainwater from a hurricane is eventually incorporated into the tree-ring, cave deposit, or reef material where it may be preserved as a long-term proxy record. The above studies are beginning to show some promise as a method of inferring aspects of past tropical cyclone activity.

Historical documents apart from traditional weather service records can also be used to reconstruct some aspects of past tropical cyclone activity. For example, investigators have used sources such as newspapers, plantation diaries, various instrumental weather records, and annals in the Caribbean to reconstruct past tropical cyclone activity in the U.S., Caribbean, Gulf of Mexico, and Atlantic basin for up to several centuries before present (Ludlam, 1963; Millas, 1968; Fernandez-Partagas and Diaz, 1996; Chenoweth, 2003; Mock, 2004; Chenoweth 
and Divine, 2008). Spanish and British historical archives may be a useful source for further investigation (Garcia Herrera et al., 2004, 2005). Even longer documentary records of tropical cyclone activity, extending back for more than 1000 years, have been found and investigated in China (Liu et al., 2001; Louie and Liu, 2003; Louie and Liu, 2004).

Using these paleoclimate proxy techniques, researchers have begun to piece together a picture of hurricane variability in certain regions over the past few hundred to few thousand years. For example, Liu and Fearn (1993; 2000) have constructed a 5,000-year paleo record of inferred category 4 and 5 hurricane strikes in Alabama and northwestern Florida, showing pronounced long time scale variability in activity. Donnelly and Woodruff's (2007) proxy reconstruction of the past 5,000 years of intense hurricane activity in the western North Atlantic suggests that hurricane variability has been strongly modulated by El Nino during this time and that the past 250 years has been relatively active in the context of the past 5,000 years. Results from different paleotempestology studies do not always appear consistent with each other, suggestive of future work needed in intercomparison of results from multiple studies. For example, Besonen et al. (2008) report that their conclusions about activity over the last $300 \mathrm{yr}$ compared with the last $1000 \mathrm{yr}$, which was based on a reconstruction from a Boston area lake, differ from conclusions about these periods from another paleo-hurricane reconstruction from a nearby region (Long Island) by Scileppi and Donnelly (2007). Nyberg et al. (2007) suggest that major hurricane activity in the Atlantic was anomalously low in the 1970s and 1980s relative to the past 270 years. Chenoweth and Divine (2008) reach a similar conclusion, based on a 318-yr document-based record. As with Donnelly and Woodruff, these studies measures were focused in the western part of the basin (near Puerto Rico or the Lesser Antilles), and in the Nyberg et al. study, hurricane activity over a broader region was inferred indirectly through statistical associations with proxies for vertical wind shear and SSTs. Neu (2008) argues that the Nyberg et al. (2007) reconstruction probably overestimates past missing major hurricanes, based on the much smaller estimates of missing tropical storms reported by other investigators using several methodologies (see also Nyberg et al. (2008)).

Paleoclimate researchers are continuing to investigate these multiple sources of information on pre-historic tropical cyclone activity, and to validate where possible, the paleoclimate proxy records against hurricane observations from the more recent, well-observed part of the historical record. These studies should provide an increasingly useful independent source of information on the tropical cyclone-climate connection, as well as a better-constrained longterm perspective on hurricane risk from rare but extreme hurricanes. Future efforts will include expansion of geographical coverage, development of new proxies, coupling of multiple proxy sources, improved calibration, and integration with modeling and advanced statistical techniques. Woodruff et al. (2008) provide an initial example of assessing paleohurricane data through comparisons with model simulations.

\section{Use of Theory and Models to Understand Past Variations in Tropical Cyclone Activity}

Theory and models of tropical cyclone activity may provide useful information both on the interpretation of past changes in activity and on possible future changes due to such factors as greenhouse gas-induced global warming or natural climate variability. The theories include potential intensity theories as well as empirical indices which attempt to relate tropical cyclone frequency to large-scale environmental conditions. The models range from global climate models to higher resolution regional models aimed at simulating hurricane structure in more detail. 
In principle, extended integrations of global climate models allow for an assessment of the frequency, intensity, duration, structure, and tracks of tropical cyclone-like features in the model. In practice, simulation of realistic intensities and detailed structures of the TC's is hampered by the coarse resolution generally required of such global models, as discussed below. In addition, the fidelity of the global model's TC genesis process compared to the real world has not been well established.

In this section, the utility of the theoretical and modeling approaches is assessed based on analyses of past interdecadal variations and trends. The capabilities of these approaches for simulating present-day climatologies, seasonal cycles, and interannual $(<10 \mathrm{yr})$ variability of TCs are discussed in detail in the Carmargo et al. chapter of this book.

\subsection{Assessment of Simulated Decadal Variability of Tropical Cyclone Activity}

In a coarse-grid global model investigation of interdecadal variability of tropical storm occurrence in the Atlantic, Vitart and Anderson (2001) were able to simulate a decrease in tropical storm frequency for the 1970s in comparison to the $1950 \mathrm{~s}$, similar to observations, by specifying the observed SST changes for the globe (and specifically for the tropical North Atlantic) in their model. The decreased frequency in their model was linked to increased vertical wind shear and reduced CAPE in the tropical storm formation regions. A correlation of hurricane activity with tropical vertical wind shear has also been noted in observational studies of Atlantic TC variability (e.g., Goldenberg et al., 2001; Bell and Chelliah, 2006).

Using a regional model dynamical downscaling approach, Knutson et al. (2007) were able to reproduce the observed multidecadal increase of Atlantic hurricane activity since 1980 as well as El Nino/La Nina modulations of Atlantic storm activity. They used
NCEP Reanalysis and observed SST variability to maintain the evolving large-scale solution close to the observed throughout the simulation period by an interior spectral "nudging" technique. Within this large-scale state, their 18-km grid nonhydrostatic model generated interannual variability of Atlantic hurricanes that closely approximated that observed during 1980-2005 (correlation of 0.86 in a two-member ensemble). Similarly, Emanuel et al. (2008) demonstrated that their statistical-deterministic downscaling framework has substantial skill at hindcasting interannual and interdecadal variations in tropical cyclone activity, when driven by information from atmospheric reanalyses. Their simulated Atlantic basin power dissipation index (1980-2006) correlated with the observed with $r=0.7$, and for global power dissipation, the correlation was 0.47 . With the exception of the eastern North Pacific, the simulated PDI shows substantial increases that are in good agreement with those derived from Best Track data, though not in agreement, outside of the Atlantic, with the reanalysis of tropical cyclone PDI undertaken by Kossin et al. (2007). In an even less constrained setting than the above two studies, LaRow et al. (2008) were able to reproduce the interannual variability of Atlantic tropical activity, using only observed SSTs in a global atmospheric model with $\sim 100 \mathrm{~km}$ grid spacing. For a four-member ensemble for the years 19862005 , they report a rank correlation of 0.78 for tropical storm counts.

\subsection{Assessment of Observed Trends in TC Activity and Related Measures}

The substantial increases in tropical cyclone Power Dissipation Indices (PDIs) reported by Emanuel (2005a) and the reported increases in the numbers and percentages of TCs attaining category 4 or 5 intensity (Webster et al., 2005) raise the question of whether these changes can be reconciled with existing theory or modeling work. Some studies have demonstrated that 
dynamical or statistical-deterministic downscaling models can reproduce the rise in metrics such as PDI or ACE since 1980 in the Atlantic (Knutson et al., 2007) or Atlantic and NW Pacific basins (Emanuel et al., 2008) when constrained by observed SSTs and atmospheric reanalyses. While LaRow et al. (2008) demonstrate that their $100 \mathrm{~km}$ grid atmospheric model can reproduce the interannual variability of Atlantic ACE well over 1986-2005 using only SSTs as boundary conditions, their model's simulated trend in ACE over the period is smaller than observed. However, none of the above studies addresses the underlying cause of the changes in SSTs and reanalysis fields over the periods studied.

The idealized modeling study of Knutson and Tuleya $(2004 ; 2005)$ found a peak hurricane wind speed sensitivity - to $\mathrm{CO}_{2}$-induced climate warming - of about $3.3 \%$ per degree Celsius (or $3.7 \%$ per degree Celsius if maximum winds are inferred from central pressures following Landsea, 1993). This sensitivity is similar to that from earlier theoretical considerations (e.g., Emanuel, 1987).

Using potential intensity theory and empirical statistical analysis, Emanuel (2007a) finds that the variability of PDI since 1980 (on time scales of more than a few years) is explained by variations in potential intensity, low-level vorticity, and vertical wind shear. These three factors covary in the Atlantic on time scales of a few years or more, but not in the Pacific, where the correlation of PDI with local SST is still present though considerably weaker. Emanuel's analysis attributes the $10 \%$ increase in potential intensity in the Atlantic and $6 \%$ increase in the NW Pacific over the past 25 years to increasing net radiative flux into the ocean and decreasing tropopause temperatures in the reanalysis. However, the underlying causes of these changes (e.g., anthropogenic vs. natural variability) remains to be determined. The highly idealized studies of $\mathrm{CO}_{2}-$ induced climate change impacts imply a much smaller sensitivity of potential intensity to SST changes than has been found (Emanuel, 2007a) for recent climate change. As noted above, the recent changes in potential intensity inferred from observations have been driven by a number of factors in addition to SSTs whose relation to increases in greenhouse forcing is unclear.

Michaels et al. (2006) hypothesized that Atlantic tropical cyclones respond to an SST threshold such that major hurricanes are possible only for storms experiencing SSTs above the threshold value at some point in their lifetime. Using a statistical-analog approach, they infer an intensity sensitivity of about $6.3 \%$ in wind speed for a 2-3 deg C SST rise. These results were challenged by Emanuel (2007b), who pointed out that there is no physical basis for a threshold SST and that Michaels et al. had erred in confusing spatial variations in activity, which depend largely on strong gradients in the level of neutral buoyancy for deep convection, with temporal changes, which depend more directly on SST and tropopause temperature.

To date, only one coupled modeling study (Bengtsson et al. 2007) has reported on attempts to simulate the 20th century variability in tropical storm counts using historical radiative forcing. In their hindcasting experiment, they simulated little change in storm counts between 1860-1900 and the period 1900-2000, despite cooler tropical SSTs in the earlier period.

Vecchi and Soden (2007a) present potential intensity estimates for 1880 to 2006 based on climate models forced by three different historical SST reconstructions. Their results illustrate how long-term changes in potential intensity are more closely tied to patterns of SST changes than to local SST changes. A similar nonlocal SST control was reported based on an observational analysis of TC intensities by Swanson (2007, 2008), and for Atlantic hurricane activity, a similar result was also inferred by Latif et al. (2007) from simulations of vertical wind shear. As a result of such nonlocal effects, despite surface warming in the Atlantic, NW Pacific, and North Indian Ocean tropical cyclone regions since the late 1800 s, 
Vecchi and Soden (2007a) argue that potential intensity on average has declined in the NW Pacific, increased in the North Indian Ocean, and that Atlantic basin potential intensity may have peaked in the 1930s and 1950s, with recent values being close to the long-term average.

Caron and Jones (2008) use two empirical genesis parameters together with CMIP3 (IPCC AR4) model simulations of the 20th century to explore possible changes in tropical cyclone activity over that period. Their primary method uses information about convective precipitation from a climate model in place of SST threshold approach similar to that originally proposed by Royer et al. (1998). Using this method, little or no upward trend in global or North Atlantic TC numbers is inferred for the 20th century. As they note, caution is required when applying a genesis parameter developed for present day climate to past or future predictions as the statistical relationships may not be valid under altered climate conditions (Ryan et al., 1992).

In previous sections, we noted that there remains considerable uncertainty over whether a significant long-term increase in tropical cyclone activity has been observed, particularly after consideration of uncertainties in earlier TC records is accounted for. Therefore, it is premature to judge whether current modeling efforts such as those reported above are consistent or inconsistent with the observational record, particularly for the nonlandfalling storms prior to the aircraft reconnaissance and satellite eras.

\section{Simulations of Future Tropical Cyclone Behavior}

\subsection{Global and Regional Nested Models}

Future changes in tropical storms projected by global or regional climate models (RCMs) are subject to many sources of uncertainty, including the future climate forcing scenario, initial conditions, regional patterns and magnitudes of future climate change for various fields, model physics and dynamics, how tropical cyclones are identified and counted, and so forth. Since tropical storms are relatively rare events, large samples sizes (i.e. many years) are typically required to test the significance of any changes against natural variability, depending upon the metric being examined. The changes in frequency of storms simulated by models are often smaller than the climatological bias of the models. These errors in the tropical storm climatology add to the uncertainty of the future changes in tropical storms projected by the models.

\subsubsection{Tropical cyclone frequency}

The combined effect of all the sources of uncertainty is that there is large overall uncertainty in future changes in tropical cyclone frequency as projected by climate models forced with future greenhouse gases. The Fourth Assessment Report (IPCC 2007) concluded that a synthesis of model results showed a "less certain possibility of a decrease in the number of relatively weak tropical cyclones, increased numbers of intense tropical cyclones and a global decrease in total numbers of tropical cyclones". Results from a number of studies, including some not available for IPCC (2007) are shown in Table 1. A caveat of these results is that it is not always clear in a particular study whether reported changes are greater than the model's natural variability, or that natural variability of $\mathrm{TC}$ formation rates or the mechanism of the TC genesis process is properly simulated in the models.

The results in Table 1 span a range of GCMs $(200 \mathrm{~km}-20 \mathrm{~km})$, regional models, and idealized frameworks. The global models tend to show a signal of fewer tropical cyclones globally in a warmer climate, though this finding is still not conclusive. Also, while most global models show a global decrease in frequency (e.g., Sugi et al., 2002; McDonald et al., 2005; Bengtsson et al., 2006; Oouchi et al., 2006), there are regional variations in the sign of the changes, and the 


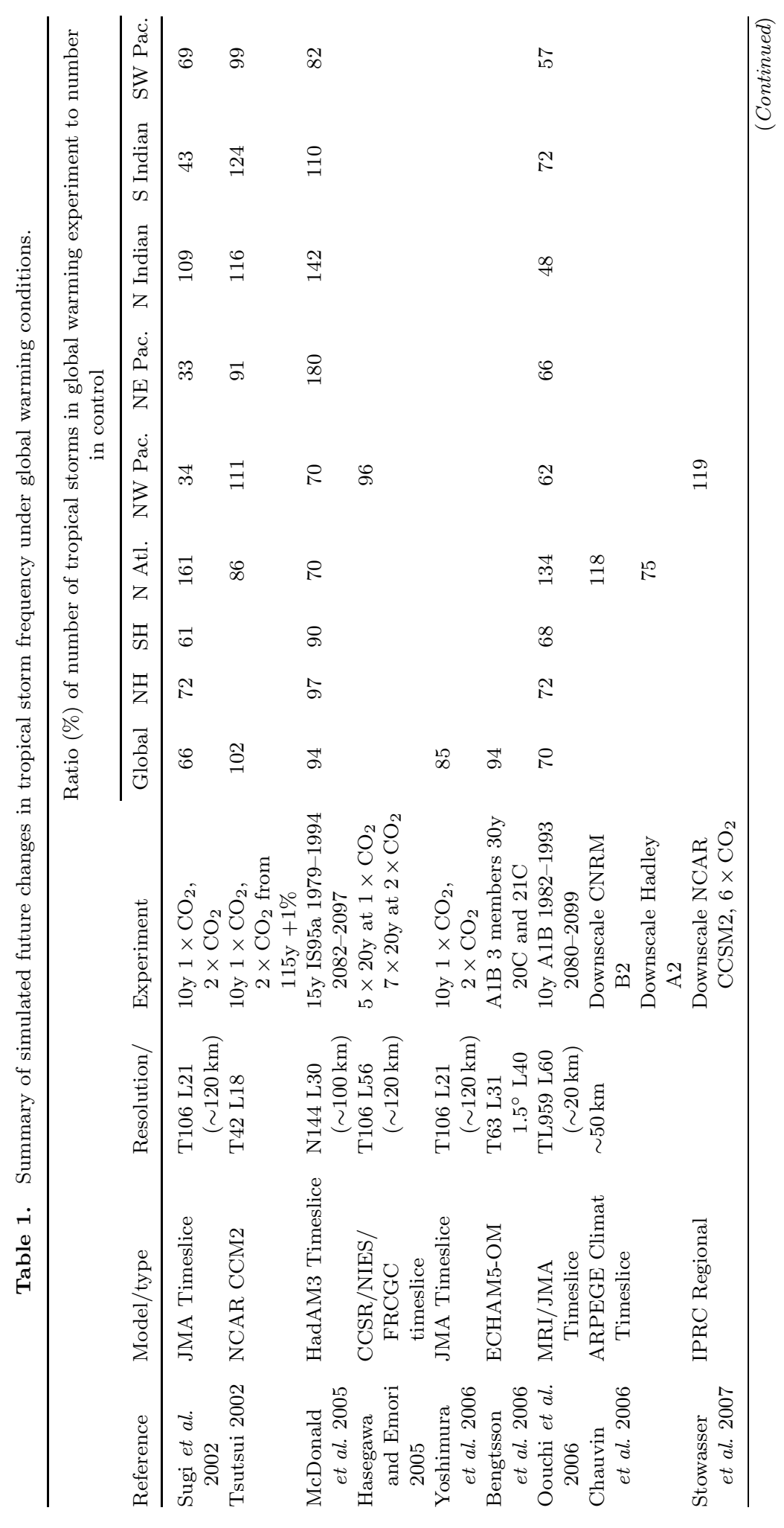




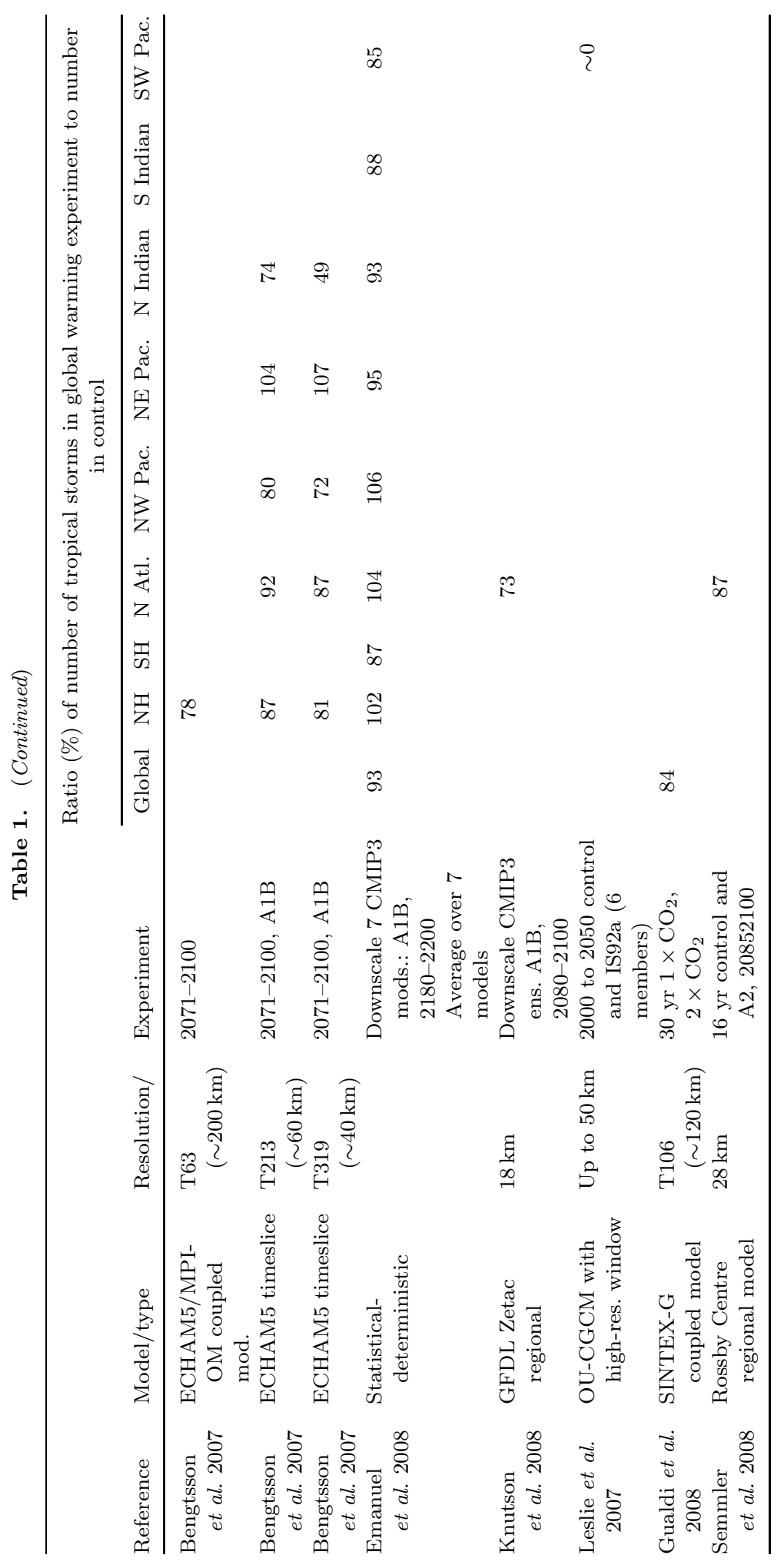


regional results vary substantially, even as to the sign of the changes, between models. The North Atlantic basin column in Table 1 illustrates the strong model dependence of results. For example, more storms are projected in the North Atlantic region in some models, despite a large reduction globally (Sugi et al., 2002; Oouchi et al., 2006), while fewer Atlantic TCs are projected by the N144 HadAM3 atmosphere only model (McDonald et al., 2005). Chauvin et al. (2006) found that the sign of the changes in tropical cyclone frequency in the north Atlantic basin depended on the SST anomaly pattern in their stretched grid global model experiments ( $50 \mathrm{~km}$ over the Atlantic region). For the Australia region, Walsh et al. (2004) used a $30 \mathrm{~km}$ grid nested regional model and found little change in frequency of tropical cyclones near Australia in their $3 \times \mathrm{CO}_{2} \mathrm{RCM}$ experiments. Using a regional model downscaling approach for the NW Pacific basin, Stowasser et al. (2007) reported only a small statistically insignificant increase in tropical cyclone frequency in response to a very large climate change perturbation $\left(6 \times \mathrm{CO}_{2}\right)$.

Although Oouchi et al. (2006) simulated an increase in future TC frequency in the Atlantic basin, they sampled relatively short periods (20 years) from a single pair of experiments in order to examine greenhouse gas-induced changes. However, internal multidecadal variability in the Atlantic in their model, similar to the AMO mechanism proposed by Goldenberg et al. (2001), conceivably could produce changes in tropical-cyclone-relevant fields (such as wind shear) between two 20-year periods that are larger in terms of TC influence than the changes produced by the radiative perturbation they focused on in their study. Therefore further experimentation with their model needs to be done to place their results in the context of internal climate variability.

Building on the theme of using multiple climate model projections to assess uncertainty in future TC behavior, Vecchi and Soden (2007b) examined the changes in tropical climate characteristics believed to be important for tropical cyclone activity using outputs from a large ensemble of CMIP3 models (Meehl et al., 2007) used for the IPCC AR4 assessment. An important feature of their multi-model ensemble mean projection results was a SWNE oriented band extending across the Atlantic basin of projected less favorable conditions for tropical cyclogenesis and intensification, including enhanced vertical wind shear, reduced mid-tropospheric relative humidity, and slight decrease in potential intensity. The enhanced vertical shear feature also extends into the main cyclogenesis region of the Eastern Pacific basin; the changes in shear are relatively minor over the Atlantic Main Development Region. Physically, this projection was related to the weakening of the east-west oriented Walker Circulation in the Pacific region (Vecchi et al., 2006), similar to that occurring during El Nino events. In contrast to the Atlantic, the West Pacific and Indian Oceans conditions during northern summer are projected to be more favorable for tropical cyclogenesis and intensification by these measures, with reduced vertical wind shear and increased potential intensity over most of these regions. Vecchi and Soden (2007b) also explored the consistency and range of responses of these regional climate change features among different models - an important source of uncertainty in future TC projections.

To test the impact of the late 21st century multi-model ensemble mean atmospheric changes for the Atlantic basin reported by Vecchi and Soden (2007b), Knutson et al. (2008) used a regional downscaling simulation of TC activity. Their control model (Knutson et al., 2007) was able to reproduce the observed rise and much of the interannual variation in Atlantic hurricane counts and other metrics, when forced with observed SSTs and large-scale atmospheric conditions from reanalyses over the period 1980-2006. After modifying the largescale climate according to the late 21st century changes projected by the ensemble of CMIP3 models, they find that Atlantic hurricane and 
tropical storm frequency were substantially reduced, by $27 \%$ and $18 \%$, respectively.

Another approach to using multiple climate model projections for TC assessment was introduced by Emanuel et al. (2008), based on an idealized statistical deterministic model. This technique again shows considerable skill when run under present day climate conditions from atmospheric reanalyses. Run separately for late 22nd century climate warming scenarios from seven different CMIP3 models, the framework projects a mixture of increases and decreases of TC frequency across different basins, with the projected changes generally being relatively modest in magnitude $(-26 \%$ to $+14 \%)$ considering the substantial increases in tropical sea surface temperatures in the climate models. The frequency of tropical storms decreases in the southern hemisphere and north Indian oceans, increases in the western North Pacific, and is indeterminate in other regions.

There is no evidence from any models to date that the region of TC formation (e.g., Knutson et al., 2008) or strong tropical convective activity (e.g., Dutton et al., 2000) increases dramatically as the area of oceanic regions with SSTs larger that $26-27^{\circ} \mathrm{C}$ expands due to greenhouse warming. Rather, model results (e.g., Knutson et al., 2008) suggest that the apparent threshold for TC formation (as diagnosed empirically for the present climate) is actually a climate-dependent threshold, which rises roughly along with the tropical mean SST increase in greenhouse warming experiments.

An important issue is to identify the underlying mechanisms producing changes in future TC behavior in the GCM simulations and regional downscaling experiments. Sugi et al. (2002) report that the simulated reduction of global TC frequency in their model was closely related to the weakening of tropical circulation, which in turn resulted from a considerable increase in the dry static stability, coupled with relatively little increase in the precipitation. Held and Soden (2006) noted that a weakening of the total upward convective mass flux in the tropics was implied as a consequence of the slower fractional rate of increase of tropical precipitation compared to lower tropospheric specific humidity in greenhouse warming simulations. However, they did not link this mechanism to smaller-scale phenomena such as tropical storms. Yoshimura and Sugi (2005) performed a series of experiments to test the relative effects of changes in SST and $\mathrm{CO}_{2}$ upon changes in TC frequency in their model. They found that the decrease in tropical storm frequency in their model was due to the increased $\mathrm{CO}_{2}$ (see also Sugi and Yoshimura, 2004), with the SST changes having a relatively small direct impact. This finding has not yet been confirmed by other studies. Emanuel et al. (2008) found that the global reduction in TC frequency in their statistical/dynamical downscaling framework was primarily due to an increase in the saturation deficit of the middle troposphere in the warm climate scenario. Regarding the regional variations in projected TC frequencies, the results of Sugi et al. (2002) and McDonald et al. (2005) and Chauvin et al. (2006) suggest that dynamical factors such as low level vorticity and vertical wind shear play a more important role than thermodynamical factors such as SST and moist instability.

\subsubsection{Tropical cyclone intensity}

Concerning future changes in TC intensity, there is substantial disagreement among recent global and regional modeling studies, although all of the highest resolution models $(\sim 50 \mathrm{~km}$ grid spacing or finer) currently available show evidence for some increase of intensity.

For global models, as discussed earlier, simulated future changes of intensity in current global models may not be reliable, since these models do not simulate the very intense TCs observed in the present climate, even in the case of the relatively high resolution $(20 \mathrm{~km}$ grid) simulation of Oouchi et al. (2006). Given this caveat, Tsutsui (2002), McDonald et al. (2005) and Oouchi et al. (2006) all report 
evidence for intensity increases, while Sugi et al. (2002), Bengtsson et al. (2006), and Hasegawa and Emori (2005; western North Pacific only), Chauvin et al. (2006; North Atlantic only), and Gualdi et al. (2008) found either no increase or a decrease of intensity. Among these studies, Tsutsui and Bengtsson et al. used relatively low resolution models; McDonald et al., Sugi et al., Hasegawa and Emori, and Gualdi et al. used intermediate $(\sim 120 \mathrm{~km})$ grid spacing models; while only Oouchi et al. used a relatively high resolution model. The Oouchi et al. (2006) study reports that the number of the most intense cyclones increases globally in their $20 \mathrm{~km}$ grid warming climate simulation, despite a large decrease in overall TC numbers. However, statistically significant intensity increases in their study were confined to only one or two individual basins. Bengtsson et al. (2007) presented results from a set of three global models with effective horizontal grid spacing ranging from $\sim 200 \mathrm{~km}$ to $\sim 40 \mathrm{~km}$. They found a tendency for increases in tropical storm intensities for the higher resolution model, but the increase was not seen in their lower resolution model. They interpreted these results as indicating that high resolution simulations $(\sim 40 \mathrm{~km})$ may be needed for a model to simulate increasing storm intensity in warmer climate.

Regional models provide another means of exploring the tropical cyclone intensity/climate issue. For example, Walsh et al. (2004), in a study for the Australia region with a nested regional model, found little change in overall TC frequency under $3 \times \mathrm{CO}_{2}$ conditions, but a $56 \%$ increase in the number of storms with relatively high maximum winds $(>30 \mathrm{~m} / \mathrm{sec}$ in their model), and a $26 \%$ increase in the number of storms with central pressures less than $970 \mathrm{HPa}$. Using a global model with higher resolution focused in the Southwest Pacific region, Leslie et al. (2007) also found a significant (15\%) increase in the number of most severe TCs simulated by the model, Knutson et al. (1998) simulated a significant $\mathrm{CO}_{2}$ warming-induced increase of typhoon intensities in the NW Pacific basin, based on downscaling a sample of tropical cyclones from a high $\mathrm{CO}_{2}$ scenario of a global climate model into a regional nested hurricane model. Stowasser et al. (2007) simulated a substantial increase of storm intensity in response to the climate warming from a very large $\left(6 \times \mathrm{CO}_{2}\right)$ perturbation using a $(\sim 50 \mathrm{~km}$ grid $)$ regional downscaling approach for the NW Pacific basin. They reported that notable increases, including a $50 \%$ increase in PDI for a $\sim 3^{\circ} \mathrm{C}$ tropical ocean surface warming due mainly to increased intensities, were driven in the model mainly by decreased vertical wind shear in the basin. In a regional model downscaling experiment for the tropical Atlantic using a multi-model late-21st century climate perturbation, Knutson et al. (2008) report a small increase $(\sim 1 \%$ per deg C) in tropical storm and hurricane wind speeds, although their control model did not simulate storms as strong as observed, nor did it simulate the observed dependence in the present climate of TC intensity on SST. Emanuel et al.'s (2008) statistical/deterministic downscaling approach, applied in all basins, gave a tendency for increasing intensity which, when averaged across the seven climate models they examined, ranged from about 0 to $11 \%$, depending upon the basin considered.

In summary, among current studies, experiments with higher resolution models $(<40 \mathrm{~km}$ grid spacing) typically find that hurricane intensities increase with greenhouse warming, although with substantial regional variation of the increases. The simulated storm intensification is much less evident in lower resolution models (>50 km grid), although such models probably give much less reliable information about hurricane intensity than higher resolution models. The intensification results from the higher resolution models in particular are also generally consistent with results from more idealized modeling and theoretical potential intensity studies which provide a mechanistic framework in which to interpret the intensity change. These alternative approaches are reviewed in section 6.2. 


\subsubsection{Tropical cyclone precipitation}

A number of studies have reported increases in TC-related precipitation under warming climate conditions, using global and regional models (Knutson and Tuleya, 2004; Hasegawa and Emori, 2005; Chauvin et al., 2006; Yoshimura et al., 2006; Bengtsson et al., 2007; Gualdi et al., 2008; Knutson et al., 2008). A number of investigators have interpreted the increase in hurricane-related precipitation as being due to enhanced atmospheric moisture in the warmer climate - a mechanism which has been discussed in the context of extreme precipitation in general by Trenberth (1999), Allen and Ingram (2002), and Emori and Brown (2005). Sugi et al. (2002) have noted that enhanced latent heating associated with increased TC precipitation does not necessarily lead to intensification of the TC, since the enhanced heating is balanced to some degree by enhanced adiabatic cooling for given amount of rising motion, due to the increased dry static stability in the simulated warmer climate.

Trenberth et al. (2007) used a simulation case study approach to explore precipitation in hurricanes and its dependence on environmental conditions, including idealized sea surface warming perturbation experiments. They argue that increasing atmospheric moisture content associated with human-caused global warming (Trenberth et al., 2005), together with enhanced hurricane intensities based on theory and observations (e.g., Emanuel, 2005a), implies an increase in TC-related rainfall of the order of 6 to $8 \%$ since 1970 .

Thus, several modeling studies support the notion of increasing hurricane-related precipitation rates due to greenhouse warming, while to our knowledge no modeling study to date provides compelling counter-evidence to this finding.

Despite the findings reported from a growing number of modeling studies on future projections, there is no confirmation of the above precipitation rate sensitivity from observed tropical cyclone precipitation studies. For example, Groisman et al. (2004) find no increasing trend in the total seasonal hurricane-related precipitation along the U.S. Southeast coast, despite finding that the frequency of very heavy precipitation unrelated to TCs has increased significantly in the same region and over the conterminous U.S. during the 20th century. They have not yet examined the behavior of hurricane-related precipitation on a per storm basis, and thus the time series they examine are influenced by changes in U.S. TC activity which has exhibited substantial multidecadal variability but no trend (Goldenberg et al., 2001; Landsea, 2005). Lau and Wu (2007) report that the occurrence of heavy rain events (top $10 \%$ by rain amount in 5-day averages) has increased in the tropics during 1979-2003, based on two precipitation data sets, although these data sets have trends of opposite sign from one another in total rainfall amounts. While not focusing on tropical cyclones, their study provides more suggestive observational evidence of a changing character of rainfall toward higher rates during more extreme events, in this case over tropical regions that commonly have deep convection. Trenberth and Fasullo (2008) infer an increase in surface sensible and latent heat fluxes and total precipitation from Atlantic tropical cyclones over the period 1970-2006, accompanying the increase in tropical storm and hurricane numbers over that time.

\subsection{Theoretical or Idealized Modeling Frameworks}

Thus far, almost all theoretical or idealized modeling frameworks have focused on potential future changes in the intensities of TCs. Emanuel (1987) and later Tonkin et al. (1997) first presented evidence, based on potential intensity $(\mathrm{PI})$ theory, that $\mathrm{CO}_{2}$ induced climate change as simulated by several GCMs implied significant increases in future TC intensities. Limitations of their approach were discussed in Henderson-Sellers et al. (1998). These theory-based assessments received model-based support from Knutson and Tuleya 
(1999; 2004; 2008), who used an idealized hurricane model framework to evaluate tropical climate warming scenarios from several different coupled climate models, all forced by increasing $\mathrm{CO}_{2}$ levels. Knutson and Tuleya (2008) reported a tropical cyclone intensity increase of about $3.3 \%$ per degree Celsius SST increase (3.7\% per degree C, using winds inferred from central pressures), which was roughly comparable to the increase predicted by the Holland PI theory, though somewhat larger than that predicted by the Emanuel PI for those same environments.

Vecchi and Soden (2007 a,b) show maps of the average Emanuel PI change as projected by a 22-member ensemble of CMIP3 global models for the late 21st century. For the hurricane season in the northern hemisphere (June-November), their results show a general increase in most tropical storm regions of up to about $2 \mathrm{~m} / \mathrm{sec}$ per degree $\mathrm{C}$ global temperature increase. In the Atlantic, the projected PI increases were smaller on average than for other basins, with even a region of slight projected decrease of PI in the mid-Atlantic basin. Averaged over a region surrounding the U.S. Southeast and Gulf coast along with the Greater Antilles (18-35 N, 90-60 W), the projected average percentage change was about $+1.3 \%$ per ${ }^{\circ} \mathrm{C}$ tropical SST change (G. Vecchi, personal communication, 2007). In contrast to the more mixed changes in the Atlantic, they found that the CMIP3 ensemble projected an increase in PI over almost the entire northern Indian and north Pacific TC basins. Southeast of Hawaii, particularly large percentage changes were projected, reaching about $7 \% /{ }^{\circ} \mathrm{C}$ (Vecchi and Soden, 2007b).

The above methods attempt to account for changes in atmospheric temperature above the warming sea surface - an effect which acts to limit the increase of intensity for a given SST increase compared to the rate in the absence of the atmospheric temperature increases (e.g., Shen et al., 2000). This influence of atmospheric temperatures is related to the work of Vecchi and Soden (2007a) and Swanson (2008). The former study connects the structure of PI change to the structure of tropical SST warming, while the latter one correlates variability of Atlantic hurricane activity to tropical Atlantic SST changes relative to changes of SST averaged over the tropics. The remote influence of nonlocal tropical SSTs is presumed to occur through an upper tropospheric temperature "bridge".

Concerning ocean coupling effects, Knutson et al. (2001) found that the $\mathrm{CO}_{2}$-warminginduced intensification of tropical cyclones in their idealized model framework was robust to the inclusion of an ocean model (i.e., cold wake in SST) beneath the storms. This finding was contradicted by Hasegawa and Emori (2007) who used a coupled global model simulation; however, the model used for the latter study had very coarse resolution ( $\sim 100 \mathrm{~km}$ grid spacing) for hurricane intensity simulation. As a further caveat, the addition of ocean coupling in their control climate simulation had only very weak impact on storm intensity $(\sim 2.5 \mathrm{Hpa})$ - a much smaller influence from ocean coupling than has been found using higher resolution hurricane prediction models (e.g., $\sim 15 \mathrm{hPa}$ in Bender and Ginis, 2000).

Wu and Wang (2004) performed an initial assessment of the potential impact of greenhouse gas-induced climate change on TC tracks using a trajectory modeling approach for the NW Pacific basin. Based on experiments derived from a particular climate model, they found evidence for inferred track changes, although the pattern of changes was fairly complex, as opposed to a more simply described, systematic change. The use of a parametric storm genesis approach for TC climate change was explored by Royer et al. (1998). Their seasonal genesis parameter was based on a measure of convective rainfall as opposed to SST or oceanic heat content. Their study found that TC frequency results for a future climate scenario depended strongly on whether the modified or unmodified genesis parameter approach was used. Using a similar approach for the CMIP3 models used in IPCC AR4, Caron and Jones (2008) find mostly small projected changes for the 21 st century in TC frequency, with a small increase projected for the northwest Pacific basin. 
The empirical genesis potential index (GPI) developed by Nolan et al. (2007) implies a positive relation between potential intensity and the likelihood of tropical cyclogenesis. Vecchi and Soden (2007b) examined the behavior of this GPI based on a multi-model ensemble of global model projections. They find for $\mathrm{NH}$ summer a substantial increase in genesis potential in the western and central Pacific, but with more modest changes elsewhere; in SH summer there were substantial increases in the South Indian Ocean, and modest changes elsewhere. In some regions potential intensity changes were quite small, or even negative, and vertical wind shear was enhanced in some regions, leading to reduced future genesis potential according to the index.

In further work aimed at increasing the realism of simulated TC genesis, Nolan et al. (2007) have undertaken a very high-resolution (4 km grid) idealized modeling approach, using the Weather Research and Forecast Model (WRF) to explore the relationship between local values of potential intensity, the Coriolis parameter, and the likelihood of tropical cyclogenesis in the absence of vertical shear. Their results show that, in radiative-convective equilibrium (RCE), the potential for TC genesis increases with increasing values of PI. The time to genesis, which decreased for increasing levels of PI, was not very sensitive to convective instability, latitude, mid-level humidity, or the GPI. They observed "spontaneous" TC genesis from random convection in $\mathrm{RCE}$, suggesting that in very ideal environments, the absence of significant precursors such as easterly waves may not be a limiting factor on TC genesis.

\section{The Role of Tropical Cyclones in the Climate System}

The possibility that tropical cyclones play an active as opposed to essentially passive role in the climate system was proposed by Emanuel (2001). According to this hypothesis, tropical cyclones, through wind-induced mixing of tropical ocean waters and subsequent re-heating of the cold wakes, make a potentially important contribution to the meridional heat transport by the oceans. Boos et al. (2004) provide additional support for this idea through idealized ocean modeling experiments. If, in a warming climate, increased tropical storm activity substantially increases the poleward heat transport by the ocean through this mechanism, this process may then help explain the occurrence of distant past climates, such as the Eocene, characterized by strongly reduced equator-to-pole temperature gradients (Emanuel, 2002). With enhanced poleward oceanic heat transport, the high latitudes would warm more than otherwise, while the warming in tropical latitudes would be moderated. This, in turn, would moderate any projected increases in tropical cyclone intensity relative to those predicted on the basis of current global climate model simulations of future climates. Sriver and Huber (2007) and Sriver et al. (2008) provide some observational evidence of this process from examination of SSTs before and after passage of tropical cyclones. Under the assumption that all of the heat mixed down from the surface translates into poleward heat transport, they estimate that a non-negligible fraction of peak ocean heat transport may be caused by ocean vertical mixing due to tropical cyclones. However, their estimates of the magnitude of this effect are smaller than originally proposed by Emanuel (2001).

Trenberth and Fasullo (2007) used a combination of hurricane best track data and high resolution hurricane simulations to estimate the aggregate surface cooling rate due to global hurricane activity of $0.33 \mathrm{~W} / \mathrm{m}^{2}$ (based on evaporation within $400 \mathrm{~km}$ of the storm centers) to $1.13 \mathrm{~W} / \mathrm{m}^{2}$ (based on storm total precipitation). They note that existing best track data, though in need of reanalysis to improve reliability, implies a positive trend since 1970 in this global surface energy loss term. We note that on decadal and longer time scales, global surface evaporation is strongly constrained by the net surface radiative balance, so excess evaporation owing to tropical cyclones must be nearly balanced by reduced evaporation elsewhere. The 
surface cooling due to storm-related evaporation presumably leads to a surface condition that is cooler than the normal climate for that region, and thus a subsequent warming of the upper ocean occurs as near-surface waters are restored toward equilibrium conditions by surface fluxes and mixing, as noted by Emanuel (2001).

Pasquero and Emanuel (2008) have used idealized models to explore the interaction between tropical cyclones and upper-ocean heat content. In these idealized settings, regimes exist with intense or weak tropical cyclone activity (with deeper mixing and larger upper-ocean heat content in the intense regime). They also found that ocean feedbacks increased the sensitivity of tropical cyclone power dissipation to climate perturbations in their model.

\section{Roadblocks to Further Advancements}

There are substantial roadblocks both in making reliable future projections of TC activity and in determining whether a trend can be detected in historical TC data.

\subsection{Data Homogeneity in Tropical Cyclone Databases}

For the climate change detection problem, a large hurdle is the quality of the tropical cyclone historical databases. The databases were populated over time without a focus on maintaining data homogeneity, a key requirement for databases which are to be used to assess possible climate-related trends. In some cases, such as the NW Pacific basin, our ability to monitor TC intensity has diminished over time. For example, aircraft reconnaissance was conducted in the NW Pacific basin beginning in the 1940s, but was discontinued in 1987. Experience with reanalysis of the HURDAT database for the Atlantic basin (Landsea et al., 2004) indicates that considerable effort and analysis is required to identify and attempt to correct, where possible, past problems with the TC databases. The possibility of such errors across all of the other ocean basins is real and problematic from both operational and climate perspectives.

Reanalysis may help provide a more uniform assessment based upon consistent use of pressure-wind relationships and flight level to surface wind analyses. Over the open oceans before that advent of satellite coverage in the $1960 \mathrm{~s}$, there will never be a complete, reliable TC dataset for any of the basins. Even in the Atlantic, aircraft reconnaissance typically only monitors roughly half of the region where tropical storms typically occur. However, it may be possible to have a high quality, global analysis of TC intensities and frequencies from about 1970 onward with substantial effort. One method that may be able to provide longer, reliable records is to focus upon analyses of landfalling tropical cyclones that have occurred along coastal regions with substantial populations. The tradeoff with this approach to get longer time series is that one only samples a much smaller number of tropical cyclones compared to the entire basin. Other approaches to estimating likely numbers of missing storms in the pre-satellite era have been discussed in section 3.2. The widespread concerns about problems in the TC databases reduces confidence in trends derived from those databases, and thus is an important roadblock to further advances in the topic of historical TC trends.

\subsection{Data Homogeneity Concerns with Other Tropical Cyclone- Related Climate Variables}

Improved understanding of the causes of past variations or trends in TC activity will depend on the existence of reliable climatequality data sets for related variables, such as SST, atmospheric temperature, moisture, wind shear, etc. Although reanalysis efforts by NCEP/NCAR and ECMWF have led to important improvements in this regard, studies 
of upper-air data sets (e.g., Santer et al., 2005; CCSP, 2006) identify likely remaining problems that could substantially affect efforts to reconcile historical TC behavior with various environmental influences. For example, if the tropical upper troposphere does not warm substantially more than the surface with greenhouse warming, as projected by climate models, the resulting destabilization would imply a larger increase in hurricane intensity, at least according to the modeling study of Shen et al. (2000). These data quality issues therefore also remain as an important roadblock for further advancement.

In using global reanalysis datasets such as NCAR/NCEP and ECMWF for TC-related studies (e.g., Sriver and Huber, 2006), inclusion of new observations over time complicates monitoring of trends of tropical cyclone statistics, as improved observations do lead to better identification of tropical cyclones (e.g., Manning and Hart, 2007). While the circulation of larger tropical cyclones can be identified on the synoptic scale, some systems remain smaller scale (mesoscale) and the region in which intensity is defined (the maximum sustained surface winds in the eyewall) is always on the mesoscale, which implies that these features typically cannot be well-represented in low resolution reanalysis products.

\subsection{Limitations of Climate Models}

Climate models contain hypotheses for how the climate system works in a framework which allows experiments to be performed to test various hypotheses or compare the model's historical simulations against historical observations. Nonetheless there are important uncertainties in climate models and the radiative forcings used for such experiments. For example, past aerosol forcing due to the interaction of aerosols with cloud and precipitation processes (indirect aerosol effects) remain quite uncertain. Climate change detection and attribution studies often rely in large part on climate model control runs for estimates of internal variability though paleo reconstructions also provide important information on this question. Climate models have known limitations in simulating some aspects of important internal modes of variability of the climate system (such as ENSO), although more recent models are improving in that regard (e.g., Wittenberg et al., 2006; Achuta-Rao and Sperber, 2006).

The climate sensitivity to past and future radiative forcing is another important area of uncertainty, both on the global scale and with respect to important regional details, as evidenced by the wide range of likely global climate sensitivity to $\mathrm{CO}_{2}$ doubling $\left(2.0-4.5^{\circ} \mathrm{C}\right)$ reported in the IPCC 4th Assessment Report (IPCC, 2007). There is considerable uncertainty in projections of future warming due to uncertainties in the climate sensitivity, in the rate of future ocean heat uptake and in various climate forcing agents, including but not limited to greenhouse gas concentrations. These combined uncertainties lead to a wide range (1.1$6.4^{\circ} \mathrm{C}$ ) in projected global warming by 2100 according to the IPCC (2007), based on a range of future emissions scenarios. For the A1B scenario, the IPCC models project a 21st century global mean warming of about $2.5^{\circ} \mathrm{C}$ on average (IPCC, 2007), compared with a smaller warming rate of about $2{ }^{\circ} \mathrm{C}$ in the tropical Atlantic (e.g., Knutson et al. 2008). Although the projected warming of tropical SSTs is generally smaller than the global mean warming, the above ranges provide an indication of the relative degree of uncertainty that also applies to future projections of tropical storm basin SSTs when forcing uncertainties are considered. The forcing-related uncertainty has not yet been formally assessed in detail at the tropical storm basin scale. In addition, there is even greater uncertainty in details of the projected pattern of SST warming in the tropics than in the tropical mean warming, and these patterns could be much more important than the average warming rate in determining an impact on tropical cyclone 
activity (e.g., Vecchi and Soden, 2007a; Knutson et al., 2008; Swanson, 2008).

The limited resolution of global climate models implies that many aspects of TC-like storms as simulated by the current models will not be very realistic, including the intensity and important smaller-scale structure such as the eye and eye-wall. This situation will gradually improve as available computing power increases (e.g., Oouchi et al., 2006). Meanwhile, questions remain about the realism of the TC genesis process in the global models. For example, the fact that the number of TCs simulated in a given model depends on physical parameter settings as well as resolution (e.g., Vitart and Stockdale, 2001) raises the question of whether some parameterizations are physically justifiable. Generally, atmosphere-only models have been used for the global model-based TC-change assessments, as available computing power has been used for increasing atmospheric resolution rather than addition of ocean coupling. Eventually, this simplification will need to be relaxed, particularly in order to explore impacts of ocean coupling on TC genesis and intensity, as well as the possible role of TCs on the climate system (section 7). The important impact of model physics and physical parameterizations, even in high-resolution models, means that future progress will depend on both increased scientific understanding and increased computing power.

\subsection{Limitations of High-Resolution Idealized Models and Theory}

While high-resolution idealized models can address the problem of limited resolution to some degree, this approach has limitations and uncertainties to be addressed. For example, the nested model used for downscaling may have a substantially different climatology and climate sensitivity from the "parent" global model, even if two-way nesting is used, whereby the fineresolution domain communicates outward and affects the solution in the low-resolution domain. This issue raises questions about the effect of such model incompatibilities (e.g., low resolution vs high resolution, physics differences, etc.) on the reliability of the overall results obtained. The simulations can also be affected by the chosen domain (e.g., Landman et al., 2005). Clearly a preferred approach would be to avoid the downscaling issue altogether by using the TC statistics from the original GCM.

The potential feedback of the TC activity on the climate system (section 7) also cannot be modeled using the simple one-way nesting approaches employed to date in $\mathrm{TC} /$ climate studies, nor can it be reliably inferred from the present generation of global models due to resolution limitations.

In contrast to the theory of potential intensity of TCs, which is more well-established, a comparable theory of $\mathrm{TC}$ frequency is not well-developed at this time. (We note that even the current theories of potential TC intensity include many assumptions and, for example, do not consider any dynamical limitations on TC intensity.) The lack of theoretical underpinning of TC genesis and frequency remains an important roadblock to progress in this area, apart from global model limitations.

\section{Proposals for Moving Forward}

In general, hurricane-climate research is expected to progress most rapidly when a combination of theory, modeling, and observations are brought to bear on the problem.

\subsection{Improved Paleoclimate, Historical, and Future Tropical Cyclone Databases}

The need for improved climate-quality tropical cyclone databases seems clear. These will provide better information for assessing future changes, and more reliable statistical assessments of past changes in hurricane activity, including land fall, in all basins. Specific examples include the need to reanalyze historical tropical cyclone databases in all basins, 
and not just the Atlantic. Such efforts should be encouraged and supported. Ideally researchers should be provided with ready access to original "raw" historical observations (i.e., ship, station, buoy, radar, aircraft, and satellite data), as well as derived quantities, from all basins concerning past tropical cyclones.

Concerning future measurement systems, we advocate a comprehensive analysis of the optimal mix of observing systems in support of tropical cyclone measurement (for climate, forecasting, and other needs). Such an analysis should include consideration of both the overall costs and benefits of different mixes of observing platforms, with researchers and forecasters providing hard data on the benefits that a given mix of platforms can provide. As an example, aircraft reconnaissance was conducted in the NW Pacific basin beginning in the 1940s, but was discontinued in 1987 in favor of satellite-only intensity estimation. Is a resumption or initiation of manned or unmanned aircraft reconnaissance in various basins now justifiable in terms of costs, benefits, and alternative measurement techniques? Another alternative that may be worth pursuing is a next generation scatterometer with finer resolution and less difficulties of wind retrieval in heavy rain conditions, compared with the limited observational capabilities of today's QuikSCAT (Atlas et al., 1999) in tropical cyclones.

A related issue is that future improvements in observing systems will lead, unfortunately, to more discontinuities and biases unless these are recognized and addressed. For example, in 2007 the U.S. Air Force reconnaissance aircraft has been outfitted with Stepped Frequency Microwave Radiometers to better provide continuous surface wind estimates for the first time (Uhlhorn and Black, 2003). Researchers need to be cognizant that large monitoring changes have occurred in the past and will continue to occur in the future, which can make determining actual climate-related trends problematic.

Studies of how sampling can alter monitoring of frequency, intensity and duration of tropical cyclones are one approach to investigating the data homogeneity issue. For example, what would the 2005 Atlantic hurricane season look like using only the monitoring capabilities available in 1970, 1950, or 1900? Until better quantitative estimates of how the current observational network influences the determination of numbers and intensities of tropical cyclones, climate trends may be difficult to distinguish from changes induced by monitoring improvements.

Paleotempestology research, which attempts to use information in the geological record to infer pre-historic hurricane activity, should continue to receive support from funding agencies. As the techniques themselves mature, thought should be given to a transition from techniquedevelopment research to systematic surveys designed to produce a comprehensive long-term record of tropical cyclone climatology.

\subsection{Improved Dynamical Modeling of Tropical Cyclone Activity}

Tropical cyclone/climate modeling studies will benefit from efforts to improve global climate modeling in general. Higher resolution global models are being developed and refined, and future global and regional climate models will increasingly use two-way nesting or variable resolution techniques. According to Chen et al. (2007) higher resolution experiments indicate that horizontal resolutions of order $1 \mathrm{~km}$ are needed to resolve the eye and eyewall structures in a typical hurricane. Studies which focus on simulation or downscaling of TCs could benefit from more rigorous testing of model performance at simulating a wider range of $\mathrm{TC}$ metrics. For example, the ability of dynamical models to simulate known interannual or interdecadal TC variability characteristics identified in various basins (e.g., Bell and Chelliah, 2006; Chan and Liu, 2004) should be further evaluated, as attempted, for example, in some recent TC downscaling studies (Knutson et al., 2007; Emanuel et al., 2008). Further evaluations of 
seasonal variability, geographical distributions of genesis and occurrence frequency, track climatologies, and storm structure are also recommended. Many of these measures should also be examined in studies using empirical approaches such as seasonal genesis parameters (see below). For dynamical model simulations, examinations of the dependence of storm characteristics on both model resolution and physics (e.g., parameterizations) are also recommended; models simulating higher intensity storms preferably would include ocean coupling (cold wake) feedbacks.

In TC climate change experiments with climate models, statistical significance testing should be emphasized to ensure that reported changes are not simply due to limited sampling. This may be particularly important in basins such as the Atlantic which feature large multidecadal variations in some observed TC metrics. By analyzing several models using a common tropical storm counting methodology, perhaps with common adjustments for resolution effects (e.g., Walsh et al. 2007), intercomparisons of sensitivity results between different models will be more informative. Such a procedure would help reduce differences between model results arising from differing analysis techniques alone and may give insights into the tropical simulations in the models. Analysis of individual models with perturbed physics experiments can be useful in isolating mechanisms producing model behavior. In general, there is a need for more consistency of metrics of TC activity, especially across models, and to improve understanding of the physical mechanisms producing the climate-induced changes in TC behavior in the models.

\subsection{Improved Empirical Modeling of Tropical Cyclone Activity}

Exploration of empirical approaches, such as seasonal genesis parameters, should be encouraged, including testing/evaluation and improvements aimed at reproducing characteristics of historical TC activity in different basins from both observations and climate model simulations. Based on these results, these approaches may be useful for making climate change projections of TC activity, although caution must be exercised (e.g. Ryan et al., 1992). Current empirical genesis parameter approaches undoubtedly do not incorporate all processes relevant for TC formation, so further refinements would be worth pursuing.

A similar recommendation would apply to studies leading to the development of empirical approaches for tropical cyclone potential intensity. Such empirical approaches should include not only thermodynamic parameters, such as the SST and outflow temperature, but also the environmental dynamical parameters that control TC intensity, such as the vertical wind shear and translational speed (Zeng et al., 2006). Current global climate models can simulate the large-scale circulation much more realistically than the individual TCs. Thus empirical approaches with environmental parameters as input to estimate TC potential intensity should be further exploited in this area.

\section{Acknowledgments}

We acknowledge the contributions of the following colleagues as members of a writing team for a preliminary version of this paper prepared for the IWTC-VI in Costa Rica, November, 2006: Seita Emori, Jenni Evans, Greg Holland, Kam-biu Liu, Ruth McDonald, David Nolan, Masato Sugi, and Yuqing Wang. Liu and McDonald contributed significant draft material for the paleoclimate and global modeling sections. A number of colleagues provided useful reviews.

\section{References}

AchutaRao, K. and K. Sperber, 2006: ENSO simulations in coupled ocean-atmosphere models: are the current models better? Clim. Dyn., 27, 1-16. 
March 13, $2010 \quad$ 10:34 B-936 b936-ch09

Allen, M. and W. Ingram, 2002: Constraints on future changes in climate and the hydrological cycle, Nature, 419, 224-232.

Atlas, R., et al., 2001: The effects of marine winds from scatterometer data on weather analysis and forecasting, Bull. Am. Meteorol. Soc., 82, 19651990.

Barnett, T. P., D.W. Pierce, K. M. AchutaRao, P. J. Gleckler, B. D. Santer, J. M. Gregory, and W. M. Washington, 2005: Penetration of human-induced warming into the world's oceans. Science, 309, 284-287.

Bell, G. D. and M. Chelliah, 2006: Leading tropical modes associated with interannual and multidecadal fluctuations in North Atlantic hurricane activity. J. Climate, 19, 590-612.

Bender, M. A. and I. Ginis, 2000: Real-case simulations of hurricane-ocean interaction using a high-resolution coupled model: effects on hurricane intensity. Mon. Wea. Rev., 128(4), 917-946.

Bengtsson, L., K. Hodges, and E. Roeckner, 2006: Storm tracks and climate change. J. Climate, 19, 3518-3543.

Bengtsson, L., K. I. Hodges, M. Esch, N. Keenlyside, L. Kornblueh, J.-J. Luo, and T. Yamatata, 2007: How may tropical cyclones change in a warmer climate? Tellus A, 59, 539-561.

Biasutti, M. and A. Giannini, 2006: Robust Sahel drying in response to late 20th century forcings. Geophys. Res. Lett., 33, L11706.

Boos, W. R., J. R. Scott, and K. A. Emanuel, 2004: Transient diapycnal mixing and the meridional overturning circulation. J. Phys. Ocean., 34, 334-341.

Bove, M. C., J. B. Elsner, C. W. Landsea, X. Niu, and J. J. O'Brien, 1998: Effect of El Niño on U.S. landfalling hurricanes, revisited. Bull. Amer. Meteor. Soc., 79, 2477-2482.

Briggs, W. M., 2008: On the changes in number and intensity of North Atlantic tropical cyclones. J. Climate, 21, 1387-1402.

Caron, L.-P. and C. G. Jones, 2008: Analysing present, past, and future tropical cyclone activity as inferred from an ensemble of coupled global climate models. Tellus, 60A, 80-96.

CCSP, 2006: Temperature Trends in the Lower Atmosphere: Steps for Understanding and Reconciling Differences. A Report by the Climate Change Science Program and the Subcommittee on Global Change Research. [Thomas R. Karl, Susan J. Hassol, Christopher D. Miller, and William L. Murray (eds,)] Department of
Commerce, NOAA's National Climatic Data Center, Washington, DC., USA, 164 pp.

CCSP, 2008: Weather and Climate Extremes in a Changing Climate. Regions of Focus: North America, Hawaii, Caribbean, and U.S. Pacific Islands. A Report by the U.S. Climate Change Science Program and the Subcommittee on Global Change Research. [Thomas R. Karl, Gerald A. Meehl, Christopher D. Miller, Susan J. Hassol, Anne M. Waple, and William L. Murray (eds.)]. Department of Commerce, NOAA's National Climatic Data Center, Washington, D.C., USA, 164 pp.

Chan, J. C. L., 2006: Comment on "Changes in Tropical Cyclone Number, Duration, and Intensity in a Warming Environment, Science, v. 311, p. 1713 .

Chan, J. C. L., 2008: Decadal variations of intense typhoon occurrence in the western North Pacific. Proc. R. Soc. A., 464, 249-272.

Chan, J. C. L. and K. S. Liu, 2004: Global warming and Western North Pacific typhoon activity from an observational perspective. J. Climate, 17, 4590-4602.

Chang E. K. and M. Y. Guo, 2007: Is the number of North Atlantic tropical cyclones significantly underestimated prior to the availability of satellite observations? Geophys. Res. Lett., 34, L14801.

Chauvin, F., J.-F. Royer, and M. Déqué, 2006: Response of hurricane-type vortices to global warming as simulated by ARPEGE-Climat at high resolution. Clim. Dyn., 27, 377-399

Chen, S. S., J. F. Price, Z. Wei, M. A. Donelan, and E. J. Walsh, 2007: The CBLAST-Hurricane Program and the next-generation fully coupled atmosphere-wave-ocean models for hurricane research and prediction. Bull. Amer. Meteor. Soc., 88(3), 311-317.

Chenoweth, M., 2003: The 18th century climate of Jamaica, derived from the journals of Thomas Thistlewood, 1750-1786. Trans. Am. Philos. Soc., 93(2).

Chenoweth, M. and D. Divine, 2008: A documentbased 318-year record of tropical cyclones in the Lesser Antilles, 1690-2007. Geochem., Geophys., Geosys., 9, Q08013.

Delworth, T. L. and T. R. Knutson, 2000: Simulation of early 20th century global warming. Science, 287(5461), 2246-2250.

Delworth, T. L. and M. E. Mann, 2000: Observed and simulated multidecadal variability in the Northern Hemisphere. Clim. Dyn., 16(9), 661-676. 
Delworth, T. L., R. Zhang, and M. E. Mann, 2007: Decadal to Centennial variability of the Atlantic from observations and models. In Ocean Circulation: Mechanisms and Impacts, Geophys. Mono. Ser. 173, Washington, DC: American Geophysical Union; 131-148.

DeMott, C. A. and D. A. Randall, 2004: Observed variations of tropical convective available potential energy. J. Geophys. Res., 109, D02102.

Donnelly, J. P., S. S. Bryant, J. Butler, J. Dowling, L. Fan, N. Hausmann, P. Newby, B. Shuman, J. Stern, K. Westover, and T. Webb, III, 2001a: A 700 yr sedimentary record of intense hurricane landfalls in southern New England. Geol. Soc. Amer. Bull., 113, 714-727.

Donnelly, J. P., S. Roll, M. Wengren, J. Butler, R. Lederer, and T. Webb, III, 2001b: Sedimentary evidence of intense hurricane strikes from New Jersey. Geology, 29, 615-618.

Donnelly, J. P. and T. Webb, III, 2004: Backbarrier sedimentary records of intense hurricane landfalls in the northeastern United States. In: Hurricanes and Typhoons: Past, Present, and Future (eds. R.J. Murnane, R. J. and K-b. Liu), pp. 58-95, Columbia University Press.

Donnelly, J. P., J. Butler, S. Roll, M. Wengren, and T. Webb, III, 2004: A backbarrier overwash record of intense storms from Brigantine, New Jersey. Marine Geology, 210, 107-121.

Donnelly, J. P. 2005: Evidence of past intense tropical cyclones from backbarrier salt pond sediments: a case study from Isla de Culebrita, Puerto Rico, USA. J. Coastal Res., 42, 201-210.

Donnelly, J. P. and J. D. Woodruff, 2007: Intense hurricane activity over the past 5,000 years controlled by El Nino and the West African monsoon. Nature, 447, 465-468.

Dunion, J. P. and C. S. Velden, 2004: The impact of the Saharan air layer on Atlantic tropical cyclone activity. Bull. Am. Meteorol. Soc., 85(3), 353365.

Dutton, J. F., C. J. Poulsen, and J. L. Evans, 2000: The effect of global climate change on the regions of tropical convection in CSM1. Geophys. Res. Lett., 27, 3049.

Elsner, J. B., 2006: Evidence in support of the climate change-Atlantic hurricane hypothesis. Geophys. Res. Lett., 33, L16705.

Elsner, J. B., 2007: Granger causality and Atlantic hurricanes. Tellus, 59, 476-485.

Elsner, J. B. and T. H. Jagger, 2008: United States and Caribbean tropical cyclone activity related to the solar cycle. Geophys. Res. Lett., 35, L18705.
Elsner, J. B., T. H. Jagger, and A. A. Tsonis, 2006: Estimated return periods for Hurricane Katrina. Geophys. Res. Lett., 33, L08704.

Elsner, J. B., J. P. Kossin, and T. H. Jagger, 2008: The increasing intensity of the strongest tropical cyclones. Nature, 455, 92-95.

Elsner, J. B., K-b. Liu, and B. L. Kocher, 2000: Spatial variations in major U.S. hurricane activity: Statistics and a physical mechanism. J. Climate, 13, 2293-2305.

Elsner, J. B., A. A. Tsonis, and T. H. Jagger, 2006: High-frequency variability in hurricane power dissipation and its relationship to global temperature. Bull. Amer. Meteor. Soc., 87, 763-768.

Emanuel, K. A., 1987: The dependence of hurricane intensity on climate. Nature, 326, 483-485.

Emanuel, K. A., 1999: Thermodynamic control of hurricane intensity. Nature, 401, 665-669.

Emanuel, K., 2000: A statistical analysis of tropical cyclone intensity. Mon. Wea. Rev., 128, 1139-1152.

Emanuel, K. A., 2001: The contribution of tropical cyclones to the oceans' meridional heat transport. J. Geophys. Res., 106, D14, 14,77114,781 .

Emanuel, K., 2002: A simple model of multiple climate regimes. J. Geophys. Res., 107(0).

Emanuel, K. A., 2005a: Increasing destructiveness of tropical cyclones over the past 30 years. Nature, 436, 686-688.

Emanuel, K. A., 2005b: Emanuel replies. Nature, 438.

Emanuel, K., 2007a: Environmental factors affecting tropical cyclone power dissipation. J. Climate, 20, 5497-5509.

Emanuel, K., 2007b: Comment on "Sea-surface temperatures and tropical cyclones in the Atlantic basin" by Patrick J. Michaels, Paul C. Knappenberger, and Robert E. Davis. Geophys. Res. Lett., 34.

Emanuel, K., R. Sundararajan, and J. Williams, 2008: Hurricanes and global warming: results from downscaling IPCC AR4 simulations. Bull. Amer. Meteor. Soc., 89(3), 347-367.

Emori, S. and S. J. Brown, 2005: Dynamic and thermodynamic changes in mean and extreme precipitation under changed climate. Geophys. Res. Lett., 32, L17706.

Enfield, D. B. and L. Cid-Serrano, 2008: Secular and multidecadal warmings in the North Atlantic and their relationships with major hurricane activity. Accepted in International Journal of Climatology. 
March 13, $2010 \quad$ 10:34 B-936 b936-ch09

Enfield, D. B. and A. M. Mestas-Nuñez, 2000: Global modes of ENSO and non-ENSO SST variability and their associations with climate. In: El Niño and the Southern Oscillation: Multiscale Variability and Global and Regional Impacts, H.F. Diaz and V. Markgraf, eds., Cambridge University Press p. 89-112.

Evan, A. T., J. Dunion, J. A. Foley, A. K. Heidinger, and C. S. Velden, 2006: New evidence for a relationship between Atlantic tropical cyclone activity and African dust outbreaks, Geophys. Res. Lett., 33, L19813.

Fernandez-Partagas, J. and H. F. Diaz, 1996: Atlantic hurricanes in the second half of the nineteenth century. Bull. Amer. Meteor. Soc., 77, 2899-2906.

Frappier, A. B., D. Sahagian, S. J. Carpenter, L. A. Gonzalez, and B. R. Frappier, 2007: A stalagmite stable isotope record of recent tropical cyclone events. Geology, 35, 110-114.

Free, M., M. Bister, and K. Emanuel, 2004: Potential intensity of tropical cyclones: comparison of results from radiosonde and reanalysis data. J. Climate, 17, 1722-1727.

Fu, Q., C. M. Johanson, S. G. Warren, and D. J. Seidel, 2004: Contribution of stratospheric cooling to satellite-inferred tropospheric temperature trends. Nature, 429, 55-58.

Garcia Herrera, R., L. Gimeno, P. Ribera, and E. Hernandez, 2005: New records of Atlantic hurricanes from Spanish documentary sources. J. Geophys. Res., 110, D03109.

Garcia Herrera, R., F. Rubio, D. Wheeler, E. Hernandez, M. R. Prieto, and L. Gimero, 2004: The use of Spanish and British documentary sources in the investigation of Atlantic hurricane incidence in historical times. In: Hurricanes and Typhoons: Past, Present, and Future (eds. R.J. Murnane, R. J. and K-b. Liu), pp. 149-176. Columbia University Press.

Gettelman, A. D., J. Seidel, M. C. Wheeler, and R. J. Ross, 2002: Multidecadal trends in tropical convective available potential energy. J. Geophys. Res., 107, 4606.

Goldenberg, S. B., C. W. Landsea, A. M. MestaNuñez, and W. M. Gray, 2001: The recent increase in Atlantic hurricane activity: causes and implications. Science, 293, 474-479.

Gray, W. M., 1990: Strong association between West African rainfall and U.S. landfall of intense hurricanes. Science, 249, 1251-1256.

Groisman, P. Y., R. W. Knight, T. R. Karl, D. R. Easterling, B. Sun, and J. H. Lawrimore, 2004: Contemporary changes of the hydrological cycle over the contiguous United States: trends derived from in situ observations. J. Hydormeteor., 5, 64-85.

Gualdi, S., E. Scoccimarro, and A. Navarra, 2008: Changes in tropical cyclone activity due to global warming: results from a high-resolution coupled general circulation model. J. Climate, 21, 52045228.

Harper, B. A., S. A. Stroud, M. McCormack, and S. West, 2008: A review of historical tropical cyclone intensity in northwestern Australia and implications for climate change trend analysis. Aust. Met. Mag., 57, 121-141.

Hasegawa, A. and S. Emori, 2005: Tropical cyclones and associated precipitation over the Western North Pacific: T106 atmospheric GCM simulation for present-day and doubled $\mathrm{CO}_{2}$ climates. SOLA, 1, 145148, SOI:10.2151/sola. 2005-038.

Hasegawa, A. and S. Emori, 2007: Effect of air-sea coupling in the assessment of $\mathrm{CO}_{2}$-induced intensification of tropical cyclone activity. Geophys. Res. Lett., 34, L05701.

Hayne, M. and J. Chappell, 2001: Cyclone frequency during the last 5,000 years from Curacoa Island, Queensland. Palaeogeography, Palaeoclimatology, Palaeoecology, 168, 201-219.

Held, I. M., T. L. Delworth, J. Lu, K. L. Findell, and T. R. Knutson, 2005: Simulation of Sahel drought in the 20th and 21st centuries. Proc. Nat. Acad. Sci., 102(50), 17891-17896.

Held, I. M. and B. J. Soden, 2006: Robust responses of the hydrologic cycle to global warming. $J$. Climate, 19, 5686-5699.

Henderson-Sellers, A., H. Zhang, G. Berz, K. Emanuel, W. Gray, C. Landsea, G. Holland, J. Lighthill, S-L. Shieh, P. Webster, and K. McGuffie, 1998: Tropical cyclones and global climate change: a post-IPCC assessment. Bull. Amer. Meteor. Soc., 79, 19-38.

Holland, G. J., 1997: The maximum potential intensity of tropical cyclones. J. Atmos. Sci., 54, 2519-2541.

Holland, G. J., 2007: Misuse of landfall as a proxy for Atlantic tropical cyclone activity, Eos Trans. $A G U, \mathbf{8 8}, 349,10.1029 / 2007 \mathrm{EO} 360001$.

Holland, G. J. and P. J. Webster, 2007: Heightened tropical cyclone activity in the North Atlantic: natural variability or climate trend? Philos. Trans. Roy. Soc. A, 365, 2695-2716.

Hoyos, C. D., P. A. Agudelo, P. J. Webster, and J. A. Curry, 2006: Deconvolution of the factors contributing to the increase in global hurricane intensity. Science, 312: 94-97. 
IPCC, 2007: Climate Change 200\%: The Physical Science Basis. Contribution of Working Group I to the Fourth Assessment Report of the Intergovernmental Panel on Climate Change [Solomon, S., D. Qin, M. Manning, Z. Chen, M. Marquis, K.B. Averyt, M. Tignor and H.L. Miller (eds.)]. Cambridge University Press, Cambridge, 996 pp.

Jagger, T. H. and J. B. Elsner, 2006: Climatology models for extreme hurricane winds near the United States. J. Climate, 19, 3220-3236.

Kamahori, H. N. Yamazaki, N. Mannoji, and K. Takahashi, 2006: Variability in intense tropical cyclone days in the western North Pacific. SOLA, 2, 104-107.

Karoly, D. J. and Q. Wu, 2005: Detection of regional surface temperature trends. J. Climate, 18, 4337-4343.

Klotzbach, P. J., 2006: Trends in global tropical cyclone activity over the past twenty years (19862005), Geophys. Res. Lett., 33, L10805.

Knaff, J. A., 1997: Implications of summertime sea level pressure anomalies in the tropical Atlantic region. J. Climate, 10, 789-804.

Knight, J. R., R. J. Allan, C. K. Folland, M. Vellinga, and M. E. Mann, 2005: A signature of persistent natural thermohaline circulation cycles in observed climate, Geophys. Res. Lett., 32, L20708.

Knight, J. R., C. K. Folland, and A. A. Scaife, 2006: Climate impacts of the Atlantic Multidecadal Oscillation. Geophys. Res. Lett., 33, 17, L17706.

Knutson, T. R., T. L. Delworth, K. W. Dixon, I. M. Held, J. Lu, V. Ramaswamy, D. Schwarzkopf, G. Stenchikov, and R. J. Stouffer, 2006: Assessment of twentieth-century regional surface temperature trends using the GFDL CM2 coupled models. J. Climate, 19(9), 1624-1651.

Knutson, T. R., J. J. Sirutis, S. T. Garner, I. M. Held, and R. E. Tuleya, 2007: Simulation of the recent multidecadal increase of Atlantic hurricane activity using an 18 -km-grid regional model. Bull. Amer. Meteor. Soc., 88(10), 15491565.

Knutson, T. R., J. J. Sirutis, S. T. Garner, G. A. Vecchi, and I. M. Held, 2008: Simulated reduction in Atlantic hurricane frequency under 21st century warming conditions. Nature Geoscience, 1, 359-364.

Knutson, T. R. and R. E. Tuleya, 1999: Increased hurricane intensities with $\mathrm{CO}_{2}$-induced global warming as simulated using the GFDL hurricane prediction system, Clim. Dyn., 15(7), 503-519.
Knutson, T. R. and R. E. Tuleya, 2004: Impact of $\mathrm{CO}_{2}$-induced warming on simulated hurricane intensity and precipitation: sensitivity to the choice of climate model and convective parameterization. J. Climate, 17, 3477-3495.

Knutson, T. R. and R. E. Tuleya, 2005: Reply. J. Climate, 18, 5183-5187.

Knutson, T. R. and R. E. Tuleya, 2008: Tropical cyclones and climate change: Revisiting recent studies at GFDL. In Climate Extremes and Society, R. Murnane and H. Diaz, eds., Cambridge University Press, Cambridge, 120-144.

Knutson, T. R., R. E. Tuleya, W. Shen, and I. Ginis, 2001: Impact of $\mathrm{CO}_{2}$-induced warming on hurricane intensities as simulated in a hurricane model with ocean coupling. J. Climate, 14, $2458-2468$

Knutson, T. R., R. E. Tuleya, and Y. Kurihara, 1998: Simulated increase of hurricane intensities in a $\mathrm{CO}_{2}$ warmed climate. Science, 279(5353), 1018-1020.

Kossin, J. P., K. R. Knapp, D. J. Vimont, R. J. Murnane, and B. A. Harper, 2007: A globally consistent reanalysis of hurricane variability and trends. Geophys. Res. Lett., 34, L04815.

Kossin J. P. and D. J. Vimont, 2007: A more general framework for understanding Atlantic hurricane variability and trends. Bull. Amer. Meteor. Soc., 88, 1767-1781.

Kuleshov, Y., L. Qi, R. Fawcett and D. Jones, 2008: On tropical cyclone activity in the Southern Hemisphere: trends and the ENSO connection. Geophys. Lett., 35, L14508.

Landman, W. A., A. Seth, and S. J. Camargo, 2005: The effect of regional climate model domain choice on the simulation of tropical cyclonelike vortices in the Southwestern Indian Ocean. J. Climate, 18, 1253-1274.

Landsea, C. W., 1993: A climatology of intense (or major) Atlantic hurricanes. Mon. Wea. Rev., 121, 1703-1713.

Landsea, C. W., C. Anderson, N. Charles, G. Clark, J. Dunion, J. Fernandez-Partagas, P. Hungerford, C. Neumann, and M. Zimmer, 2004: The Atlantic hurricane database reanalysis project: Documentation for the 18511910 alterations and additions to the HURDAT database. In: Hurricanes and Typhoons: Past, Present and Future, R. J. Murname and K.-b. Liu, Eds., Columbia University Press, pp. $177-221$.

Landsea, C. W., 2005: Hurricanes and global warming. Nature, 438. 
March 13, $2010 \quad$ 10:34 B-936 b936-ch09

Landsea, C. W., B. A. Harper, K. Hoarau, and J. A. Knaff, 2006: Can we detect trends in extreme tropical cyclones? Science. 313, 452-454.

Landsea, C. W., 2007: Counting Atlantic tropical cyclones back to 1900. EOS, 88, $197 \& 202$.

Landsea, C. W., D. A. Glenn, W. Bredemeyer, M. Chenoweth, R. Ellis, J. Gamache, L. Hufstetler, C. Mock, R. Perez, R. Prieto, J. Sanchez-Sesma, D. Thomas, and L. Woolcock, 2008: A reanalysis of the 1911 to 1920 Atlantic hurricane database. J. Climate, 21, 2138-2168.

LaRow, T. E., Y.-K., Lim, D. W. Shin, E. P. Chassignet, and S. Cocke, 2008: Atlantic basin seasonal hurricane simulations. J. Climate, 21, $3191-3206$

Latif, M., N. Keenlyside, and J. Bader, 2007: Tropical sea surface temperature, vertical wind shear, and hurricane development. Geophys. Res. Lett., 34, L01710.

Lau, K.-M. and H.-T. Wu, 2007: Detecting trends in tropical rainfall characteristics, 1979-2003. Int. J. Climatol., 27, 979-988.

Lawrence, J. R. and S. D. Gedzelman, 1996: Low stable isotope ratios of tropical cyclone rains. Geophys. Res. Lett., 23, 527-530.

Leslie, L. M., D. J. Karoly, M. Leplastrier, and B. W. Buckley, 2007: Variability of tropical cyclones over the southwest Pacific Ocean using a high-resolution climate model. Meteorol. Atmos. Phys., 97, 171-180.

Liu, K.-b., 2004: Paleotempestology: Principles, Methods, and Examples from Gulf Coast Lake Sediments. In: Hurricanes and Typhoons: Past, Present, and Future, R.J. Murnane, R. J. and K.-b. Liu, eds., Columbia University Press, pp. $13-57$.

Liu, K.-b. and M. L. Fearn, 1993: Lake-sediment record of late Holocene hurricane activities from coastal Alabama. Geology, 21, 793-796.

Liu, K.-b. and M. L. Fearn, 2000: Reconstruction of prehistoric landfall frequencies of catastrophic hurricanes in northwestern Florida from lake sediment records. Quaternary Research, 54, 238245.

Liu, K.-b., C. Shen, and K. S. Louie, 2001: A 1000-year history of typhoon landfalls in Guangdong, southern China, reconstructed from Chinese historical documentary records. Annals of the Association of American Geographers, 91, 453-464.

Louie, K. S. and K.-b. Liu, 2003: Earliest historical records of typhoons in China. J. Historical Geography, 29, 299-316.
Louie, K. S. and K.-b. Liu, 2004: Ancient records of typhoons in Chinese historical documents. In: Hurricanes and Typhoons: Past, Present, and Future, R.J. Murnane, R. J. and K.-b. Liu, eds., Columbia University Press, pp. 222-248.

Ludlam, D.M., 1963: Early American hurricanes, 1492-1870. American Meteorological Society.

Mann, M. and K. Emanuel, 2006: Atlantic hurricane trends linked to climate change. EOS, 87, 233241.

Mann, M. E., T. A. Sabbatelli, and U. Neu, 2007: Evidence for a modest undercount bias in early historical Atlantic tropical cyclone counts. Geophys. Res. Lett., 34, L22707.

Manning, D. and R. E. Hart, 2007: Evolution of North Atlantic ERA40 tropical cyclone representation. Geophys. Res. Lett., 34, L05705.

Marshall, G. J., P. A. Stott, J. Turner, W. M. Connolley, J. C. King, T. A. Lachlan-Cope, 2004: Causes of exceptional atmospheric circulation changes in the Southern Hemisphere. Geophys. Res. Lett., 31(14), L14205.

Maue, R. N. and R. E. Hart, 2007: Comment on "Low frequency variability in globally integrated tropical cyclone power dissipation" by Ryan Sriver and Matthew Huber. Geophys. Res. Lett., 34, L11703.

McDonald, R. E., D. G. Bleaken, D. R. Cresswell, V. D. Pope, and C. A. Senior, 2005: Tropical storms: representation and diagnosis in climate models and the impacts of climate change. Clim. Dyn., 25, 19-36.

Mears, C. A. and F. J. Wentz, 2005: The effect of diurnal correction on satellite-derived lower tropospheric temperature. Science, 309, 1548-1551.

Meehl, G. A., C. Covey, T. Delworth, M. Latif, B. McAvaney, J. F. B. Mitchell, R. J. Stouffer, and K. E. Taylor, 2007: The WCRP CMIP3 multimodel dataset: A new era in climate change research. Bull. Amer. Meteor. Soc., 88(9), 1383-1394.

Meehl, G. M., W. M. Washingon, C. M. Amman, J. M. Arblaster, T. M. L. Wigley, and C. Tebaldi, 2004: Combinations of natural and anthropogenic forcings in twentieth-century climate. J. Climate, 17, 37213727 .

Merryfield, W. J., 2006: Changes to ENSO under $\mathrm{CO}_{2}$ doubling in a multimodel ensemble. J. Climate, 19, 4009-4027.

Michaels, P. J., P. C. Knappenberger, and R. E. Davis, 2006: Sea-surface temperatures and troical cyclones in the Atlantic basin. Geophys. Res. Lett., 33, L09708. 
Millas, J. C., 1968: Hurricanes of the Caribbean and adjacent regions, 1492-1800. Academy of the Arts and Sciences of the Americas.

Miller, D. L., C. I. Mora, H. D. Grissino-Mayer, C. J. Mock, M. E. Uhle, and Z. Sharp, 2005: Tree-ring isotope records of tropical cyclone activity. Proc. Nat. Acad. Sci., 103(39), 14294-14297.

Mock, C. J., 2004: Tropical cyclone reconstructions from documentary records: examples for South Carolina, United States. In: Hurricanes and Typhoons: Past, Present, and Future, R.J. Murnane, R. J. and K.-b. Liu, eds., Columbia University Press, pp. 121-148.

Neu, U., 2008: Is recent major hurricane activity normal? Nature, 451, E5.

Nolan, D. S., E. D. Rappin, and K. A. Emanuel, 2007: Tropical cyclogenesis sensitivity to environmental parameters in radiative-convective equilibrium. Q. J. R. Meteorol. Soc., 133, 2085-2107.

Nott, J. and M. Hayne. 2001. High frequency of "super-cyclones" along the Great Barrier Reef over the past 5,000 years. Nature, 413, 508-512.

Nyberg, J., B. A. Malmgren, A. Winter, M. R. Jury, K. Halimeda Kilbourne, and T. M. Quinn, 2007: Low Atlantic hurricane activity in the 1970s and 1980s compared to the past 270 years. Nature, 447, 698-702.

Nyberg, J., B. A. Malmgren, A. Winter, M. R. Jury, K. Halimeda Kilbourne, and T. M. Quinn, 2008: Nyberg et al. reply. Nature, 451, E6.

Oouchi, K., J. Yoshimura, H. Yoshimura, R. Mizuta, S. Kusunoki, and A. Noda, 2006: Tropical cyclone climatology in a global-warming climate as simulated in a $20 \mathrm{~km}$-mesh global atmospheric model: frequency and wind intensity analysis. J. Meteorol. Soc. Japan, 84, 259-276.

Pasquero, C. and K. Emanuel, 2008: Tropical cyclones and transient upper-ocean warming. J. Climate, 21, 149-162.

Pezza, A. B. and I. Simmonds, 2005: The first South Atlantic hurricane: unprecedented blocking, low shear, and climate change. Geophys. Res. Lett., 32, L15712.

Pielke, R. A., Jr., 2005: Are there trends in hurricane destruction? Nature, 438, E11.

Pielke, R. A., J. Gratz, C. W. Landsea, D. Collins, M. A. Saunders, and R. Musulin, 2008: Normalized hurricane damage in the United States: 1900-2005. Natural Hazards Review, 9, 29-42.

Rotstayn, L. and U. Lohmann, 2002: Tropical rainfall trends and the indirect aerosol effect. J. Climate, 15, 2103-2116.

Royer. J.-F., F. Chauvin, B. Timbal, P. Araspin, and D. Grimal, 1998: A GCM study of the impact of greenhouse gas increase on the frequency of occurrence of tropical cyclones. Clim. Change, 38, 307-343.

Ryan, B. F., I. G. Watterson, and J. L. Evans, 1992: Tropical cyclones frequencies inferred from Gray's yearly genesis parameter: validation of GCM tropical climate. Geophys. Res. Lett., 19, 1831-1834.

Santer, B. D., and Coauthors, 2005: Amplification of surface temperature trends and variability in the tropical atmosphere. Science, 309, 1551-1556.

Santer, B. D., et al., 2006: Forced and unforced ocean temperature changes in Atlantic and Pacific tropical cyclogenesis regions. Proc. Nat. Acad. Sci., 103, 13905-13910, 10.1073/ pnas.0602861103.

Santer, B. D. and Coauthors, 2007: Identification of human-induced changes in atmospheric moisture content. Proc. Nat. Acad. Sci., 104, 1524815253, 10.1073/pnas.0702872104.

Saunders, M. A. and A. S. Lea, 2005: Seasonal prediction of hurricane activity reaching the coast of the United States. Nature, 434, 1005-1008.

Saunders, M. A. and A. S. Lea, 2008: Large contribution of sea surface warming to recent increase in Atlantic hurricane activity. Nature, 451, 557561.

Scileppi, E. and J. P. Donnelly, 2007: Sedimentary evidence of hurricane strikes in western Long Island, New York. Geochem., Geophys., Geosys., 8, Q06011.

Semmler, T., S. Varghese, R. McGrath, P. Nolan, S. Wang, P. Lynch, and C. O'Dowd, 2008: Regional climate model simulations of North Atlantic cyclones: frequency and intensity changes. Clim. Res., 36, 1-16.

Shen, W., R. E. Tuleya, and I. Ginis, 2000: A sensitivity study of the thermodynamic environment on GFDL model hurricane intensity: implications for global warming. J. Climate, 13, 109-121.

Sherwood, S. C., J. R. Lanzante, and C. L. Meyer, 2005: Radiosonde daytime biases and late-20th century warming. Science, 309, 1556-1559.

Soden, B. J., D. L. Jackson, V. Ramaswamy, M. D. Schwarzkopf, and X. Huang, 2005: The radiative signature of upper tropospheric moistening. Science, 310(5749), 841-844.

Solow, A. R. and A. R. Beet, 2008: On the incompleteness of the historical record of North Atlantic tropical cyclones. Geophys. Res. Lett., 35, L11803.

Solow, A. R. and L. J. Moore, 2002: Testing for trend in North Atlantic Hurricane Activity, 190098. J. Climate, 15, 3111-3114. 
March 13, $2010 \quad$ 10:34 B-936 b936-ch09

Sriver, R. and M. Huber, 2006: Low frequency variability in globally integrated tropical cyclone power dissipation. Geophys. Res. Lett., 33, L11705.

Sriver, R. and M. Huber, 2007: Observational evidence for an ocean heat pump induced by tropical cyclones. Nature, 447, 577-580.

Sriver, R., M. Huber, and J. Nusbaumer, 2008: Investigating tropical cyclone-climate feedbacks using the TRMM Microwave Imager and the Quick Scatterometer. Geochem., Geophys., Geosys., 9, Q09V11.

Stott, P. A., S. F. B. Tett, G. S. Jones, M. R. Allen, J. F. B. Mitchell, and G. J. Jenkins, 2000: External control of 20th century temperature by natural and anthropogenic forcings. Science, 290, 2133-2137.

Stowasser, M., Y. Wang, and K. Hamilton, 2007: Tropical cyclone changes in the western North Pacific in a global warming scenario. J. Climate, 20, 2378-2396.

Sugi, M., A. Noda, and N. Sato, 2002: Influence of global warming on tropical cyclone climatology: an experiment with the JMA global model. J. Meteorol. Soc. Japan, 80, 249-272.

Sugi, M. and J. Yoshimura, 2004: A mechanism of tropical precipitation change due to $\mathrm{CO}_{2}$ increase. J. Climate, 17, 238-243.

Swanson, K., 2007: Impact of scaling behavior on tropical cyclone intensities. Geophys. Res. Lett., 34, L18815.

Swanson, K., 2008: Nonlocality of Atlantic tropical cyclone intensities. Geochem., Geophys., Geosys., 9, Q04V01.

Tang, B. H. and J. D. Neelin, 2004: ENSO influence on Atlantic hurricanes via tropospheric warming. Geophys. Res. Lett., 31, L24204.

Tonkin, H., G. Holland, C. Landsea, and S. Li, 1997: Tropical cyclones and climate change: a preliminary assessment. In Assessing Climate Change: Results from the Model Evaluation and Consortium for Climate Assessments, W. Howe and A. Henderson-Sellers, eds., Taylor and Francis Group, London, pp. 327-360.

Trenberth, K., 1999: Conceptual framework for changes of extremes of the hydrological cycle with climate change. Clim. Change, 42, 327-339.

Trenberth, K., 2005: Uncertainty in hurricanes and global warming. Science, 308, 1753-1754.

Trenberth, K. E. and J. Fasullo, 2008: Energy budgets of Atlantic hurricanes and changes from 1970. Geochem., Geophys., Geosys., 9, Q09V08.

Trenberth, K. E., J. Fasullo, and L. Smith, 2005: Trends and variability in column-integrated atmospheric water vapor. Clim. Dyn., 24, 741758 .

Trenberth, K. E. and D. J. Shea, 2006: Atlantic hurricanes and natural variability in 2005. Geophys. Res. Lett., 33, L12704.

Trenberth, K. and J. Fasullo, 2007: Water and energy budgets of hurricanes and implications for climate change. J. Geophys. Res., 112, D23107.

Trenberth, K., C. A. Davis, and J. Fasullo, 2007: Water and energy budgets of hurricanes: Case studies of Ivan and Katrina, J. Geophys. Res., 112, D23106.

Tsutsui, J., 2002: Implications of anthropogenic climate change for tropical cyclone activity: a case study with the NCAR CCM2. J. Meteorol. Soc. Japan, 80, 45-65, doi: 10.2151/jmsj.80.45.

Uhlhorn, E. W. and P. G. Black, 2003: Verification of remotely sensed sea surface winds in hurricanes. J. Atmos. and Ocean. Tech., 20, 99-116.

Vecchi, G. A., A. Clement, and B. J. Soden, 2008: Examining the tropical Pacific's response to global warming. EOS, 89, 81-83.

Vecchi, G. A. and T. R. Knutson, 2008: On estimates of historical North Atlantic tropical cyclone activity. J. Climate, 21, 3580-3600.

Vecchi, G. A., B. J. Soden, A. T. Wittenberg, I. M. Held, A. Leetmaa, and M. J. Harrison, 2006: Weakening of the tropical Pacific atmospheric circulation due to anthropogenic forcing. Nature, 441, 73-76.

Vecchi, G. A. and B. J. Soden, 2007a: Effect of remote sea surface temperature change on tropical cyclone potential intensity. Nature, 450(7172), 1066-1070.

Vecchi, G. A. and B. J. Soden, 2007b: Increased tropical Atlantic wind shear in model projections of global warming. Geophys. Res. Lett., 34, L08702.

Vitart, F. and J. L. Anderson, 2001: Sensitivity of Atlantic tropical storm frequency to ENSO and interdecadal variability of SSTs in an ensemble of AGCM integrations. J. Climate, 14(4), 533-545.

Vitart, F. and T. Stockdale, 2001: Seasonal forecasting of tropical storms using coupled GCM integrations. Mon. Wea. Rev., 129, 2521-2537.

Walsh, K., 2004: Tropical cyclones and climate change: unresolved issues. Clim. Res., 27, 77-83.

Walsh, K. J. E., M. Fiorino, C. W. Landsea, and K. McInnes, 2007: Objectively-determined resolution-dependent threshold criteria for the detection of tropical cyclones in climate models and reanalyses. J. Climate, 20, 2307-2314.

Walsh, K., D. Karoly, and N. Nicholls, 2008: The detection and attribution of climate change 
March 13, $2010 \quad$ 10:34 B-936 b936-ch09

effects on tropical cyclones. To appear in: Hurricanes and Climate (J. Elsner, ed.), Springer.

Walsh, K. J. E., K.-C. Nguyen, and J. L. McGregor, 2004: Fine-resolution regional climate model simulations of the impact of climate change on tropical cyclones near Australia. Clim. Dyn., 22, $47-56$.

Wang, C. and S.-K. Lee, 2008: Global warming and United States landfalling hurricanes. Geophys. Res. Lett., 35, L02708.

Wang, C., S.-K. Lee, and D. B. Enfield, 2008: Atlantic Warm Pool acting as a link between Atlantic Multidecadal Oscillation and Atlantic tropical cyclone activity. Geochem., Geophys., Geosys., 9, Q05V03.

Webster, P. J., G. J. Holland, J. A. Curry, and H.-R. Chang, 2005: Changes in tropical cyclone number, duration, and intensity in a warming environment. Science, 309, 1844-1846.

Webster, P. J., J. A. Curry, J. Liu, and G. J. Holland, 2006: Response to comment on "Changes in tropical cyclone number, duration, and intensity in a warming environment". Science, 311, 1713c.

Wittenberg, A. T., A. Rosati, N.-C. Lau, and J. J. Ploshay, 2006: GFDL's CM2 global coupled climate models Part 3: Tropical Pacific climate and ENSO. J. Climate, 19(5), 698-722.

WMO (World Meteorological Organization), 2006: Atmospheric Research and Environment Programme. Statement on Tropical Cyclones and Climate Change, 13 pages, http://www.wmo. int/pages/prog/arep/tmrp/documents/iwtc_sum mary.pdf and Summary Statement on Tropical Cyclones and Climate Change, 1 page, http://www.wmo.int/pages/prog/arep/tmrp/ documents/iwtc_statement.pdf

Woodruff, J. D., J. P. Donnelly, K. Emanuel, and P. Lane, 2008: Assessing sedimentary records of paleohurricane activity using modeled hurricane climatology. Geochem., Geophys., Geosys., 9, Q09V10.

Wu, L. and B. Wang, 2004: Assessing impacts of global warming on tropical cyclone tracks. J. Climate, 17, 1686-1698.

Wu, L., B. Wang, and S. A. Braun, 2008: Implications of tropical cyclones power dissipation index. Int. J. Climatol., 28, 727-731.

Wu, L., B. Wang, and S. Geng, 2005: Growing typhoon influence on east Asia, Geophys. Res. Lett., 32, L18703.

Wu, M.-C., K.-H. Yeung, and W.-L. Chang, 2006: Trends in western North Pacific tropical cyclone intensity. Eos. Trans., AGU, 87(48), 537.

Yoshimura, J. and M. Sugi, 2005: Tropical cyclone climatology in a high-resolution AGCM-impacts of SST warming and $\mathrm{CO}_{2}$ increase. SOLA, 1 , 133-136.

Yoshimura, J., M. Sugi, and A. Noda, 2006: Influence of greenhouse warming on tropical cyclone frequency. J. Meteor. Soc. Japan, 84, 405-428.

Zeng, Z., Y. Wang, and C.-C. Wu, 2006: Environmental dynamical control of tropical cyclone intensity-An observational study. Mon. Wea. Rev., 135, 38-59.

Zhang, R., and T. L. Delworth, 2006: Impact of Atlantic multidecadal oscillations on India/Sahel rainfall and Atlantic hurricanes. Geophys. Res. Lett., 33, L17712.

Zhang, R., T. L. Delworth, and I. M. Held, 2007: Can the Atlantic Ocean drive the observed multidecadal variability in Northern Hemisphere mean temperature? Geophys. Res. Lett., 34, L02709.

Zhang, R., 2007: Anticorrelated multidecadal variations between surface and subsurface tropical North Atlantic. Geophys. Res. Lett., 34, L12713. 